\title{
The effect of regional warming on the East Asian summer monsoon
}

\author{
Kwang-Yul Kim ${ }^{1} \cdot$ Beom-Seok Kim ${ }^{1}$
}

Received: 10 November 2019 / Accepted: 4 February 2020 / Published online: 17 February 2020

(c) The Author(s) 2020

\begin{abstract}
East Asian summer monsoon (EASM) precipitation has changed significantly due to regional warming. In this study, effect of regional warming on the EASM summer precipitation is investigated during 1979-2018 with a particular emphasis on the frontogenesis. The frontogenetic function shows that change in circulation and temperature distribution associated with regional warming is fairly consistent with precipitation change. Specifically, changes in temperature gradient and deformation, both in terms of its magnitude and direction with respect to thermal gradient, result in cross-frontal circulation change with respect to its position and magnitude; this, in turn, is closely linked with EASM precipitation change. Due to warming, frontal circulation has weakened except in the mature stage, when the front is over the Kuroshio Current. From a slightly southward shifted position, the northward migration of the front is more precipitous than in the past reaching its northernmost latitude earlier by $\sim 2$ weeks. On the other hand, the southward migration has become slightly sluggish. In association with the frontogenesis, large-scale precipitation is more strongly affected north of $\sim 30^{\circ} \mathrm{N}$. South of $\sim 25^{\circ} \mathrm{N}$, precipitation change is due largely to convective precipitation.
\end{abstract}

Keywords East Asian monsoon $\cdot$ Frontogenesis $\cdot$ Regional warming $\cdot$ Climate change

\section{Introduction}

East Asia summer monsoon (EASM) is a term that encompasses the overall summer climate system in East Asia. East Asian summer precipitation constitutes an important element of this monsoon system and exhibits significant seasonally repeating characteristics. East Asian summer precipitation is a popular research subject, since it is closely tied with economic issues, disaster prevention, agricultural policy, water resource development plan, and so forth. Furthermore, a large number of people is affected by this climate system because of the high population density in East Asia. Accordingly, variability of the EASM rainfall and its climatic change is a scientific issue of great importance.

This study focuses on analyzing large-scale dynamical effect of regional warming on the frontogenesis and

Electronic supplementary material The online version of this article (https://doi.org/10.1007/s00382-020-05169-7) contains supplementary material, which is available to authorized users.

Kwang-Yul Kim

kwang56@snu.ac.kr

1 School of Earth and Environmental Sciences, Seoul National University, Seoul 08826, Republic of Korea precipitation associated with the EASM. According to the geographical locations in East Asia, the arrival of the EASM rainband and the subsequent rainfall period is called by various names: 'Meiyu' in China, 'Baiu' in Japan, and 'Changma' in Korea. Effort to explain the dynamical properties of the EASM rainband has a long history. Recent studies include Sampe and Xie (2010), who asserted that the westerly jet plays a role of environmental forcing for the ascending motion in the Meiyu-Baiu rainband. They pointed out that positive horizontal thermal advection by the mid-tropospheric jet induces adiabatic ascending motion to maintain thermal energy balance. As the westerly departs from the eastern flank of the Tibetan Plateau, a wide region of warm advection is developed and upwelling is stimulated over East Asia.

The idea of thermal energy being carried by the westerly jet along the monsoon rainband is expanded into advection of moist static energy by Chen and Bordoni (2014). They also proposed that the existence of Tibetan Plateau is central to the formation and evolution of the Meiyu-Baiu system. Horinouchi (2014) examined the relationship between upper-level disturbance, interpreted as Rossby waves along the jetstream, and synoptic variability of precipitation and moisture transport in summer over East Asia and the 
Northwest Pacific. By conducting potential vorticity (PV)inversion and Q-vector analysis, he elicited that secondary circulation forces upwelling relevant to precipitation band. Horinouchi and Hayashi (2017) analyzed relationship between upper-tropospheric dynamics and EASM precipitation. They showed that precipitation along the jetstream is induced predominantly by geostrophic flow regardless of the phase of upper-level disturbances.

A number of papers analyzed the relationship between the EASM rainband and summertime large-scale circulation around East Asia. Chen and Chang (1980), Ninomiya (1984), Akiyama (1990), Kodama (1992) are good references to understand fundamental dynamical nature of EASM. Yihui and Chan (2005) overviewed general properties of the EASM including its onset, evolution, contrast with the Indian Monsoon, and its variability on diverse time scales. They also asserted that internal variability of atmospheric circulation is as important for EASM variability as other well-known external forcing such as Eurasian snow cover and Pacific Ocean SST. In view of these earlier studies, atmospheric circulation change due to regional warming may significantly affect EASM rainfall.

Many of the earlier papers that explore the impact of global warming on monsoon precipitation used atmospheric modeling results (e.g. Kimoto 2005; Kitoh and Uchiyama 2006; Arai and Kimoto 2007; Kawase et al. 2009; Li et al. 2010; Zhu et al. 2012; Seo et al. 2013; Chen and Sun 2013; Hong and Ahn 2015; Zhou et al. 2017; Liu et al. 2018; Horinouchi et al. 2019; Jin and Stan 2019). It is difficult to summarize the past work in a short paragraph, since each study is conducted in a unique setting in terms of model, domain and period to address distinct aspects of climate impact on EASM precipitation. Nevertheless, a common result is that the amount of EASM precipitation has increased and the position of the monsoon rainband has shifted southward due to global warming. Through modeling efforts, one can also compare the evolution pattern and intensity of EASM precipitation among different global warming scenarios, and address future change in EASM precipitation.

In this study, however, no modeling result is used. A statistical analysis tool called the cyclostationary empirical orthogonal function (CSEOF) technique (Kim et al. 1996, Kim et al. 2015; Kim and North 1997) is used to extract the seasonal cycle of the EASM and the global warming signal from a reanalysis dataset. Based on the seasonal cycle and the warming signal, we will address how regional warming affects the seasonal cycle of the EASM. Using this decomposition, we will investigate how the precipitation pattern associated with the EASM has been changing with the changing climate and what we should expect in future if this trend continues. We will, in particular, focus on the impact of regional warming on the dynamical characteristics of the monsoonal front and associated precipitation during the past 40 years.

Information on the dataset used in this study is presented in Sect. 2. The primary tool for analysis in this study is the CSEOF technique. Section 3 discusses the basic features of CSEOF analysis and the regression analysis in CSEOF space. Results of analysis are presented in Sect. 4. The evolution pattern of East Asia summer precipitation as well as its frontal structure and cross-frontal circulation are described and contrasted between the pre-warming period and the post-warming period. Change in the frontal structure, a key element of monsoonal precipitation, is investigated at four critical stages of the EASM in this section. Section 5 summarizes the change in precipitation and frontal structure of the East Asian summer monsoon, followed by concluding remarks in Sect. 6.

\section{Data}

Data used in this study are the European Center for MediumRange Weather Forecast (ECMWF)-interim reanalysis (ERA) datasets (Dee et al. 2011) for 40 years (1979-2018). We used the records in summer from May 15 to September 11 at a 5-day resolution covering the domain $90^{\circ}-180^{\circ} \mathrm{E}$ and $0^{\circ}-60^{\circ} \mathrm{N}$ at a $1.5^{\circ} \times 1.5^{\circ}$ resolution. We analyzed the data at 23 vertical levels $(1000-200 \mathrm{hPa})$. The variables used in this study include $2 \mathrm{~m}$ (surface) air temperature, precipitation, large-scale precipitation, and convective precipitation and pressure variables such as temperature, geopotential, zonal and meridional wind, and vertical (pressure) velocity.

\section{Method of analysis}

CSEOF analysis is conducted on all variables to extract the seasonal cycle and the global warming signal. In CSEOF analysis, space-time data are decomposed as (Kim et al. 1996, 2015; Kim and North 1997).

$T(r, t)=\sum_{n} B_{n}(r, t) T_{n}(t)$,

where $B_{n}(r, t)$ are cyclostationary loading vectors (CSLVs) and $T_{n}(t)$ corresponding principle component (PC) time series. CSLVs are periodic in time,

$B_{n}(r, t)=B_{n}(r, t+d)$,

where the period $d$ is called the nested period and represents the period of the statistics of the underlying data. As in EOF analysis, CSLVs are mutually orthogonal and PCs are mutually uncorrelated, i.e., 
Fig. 1 The seasonal cycle of precipitation (shading; (1000-850 hPa) geopotential height (contoured at $3 \mathrm{~m}$ interval) and wind (vectors) over East Asia during summer 15-Jun 13, b Jun 14-Jul 13, c Jul 14-Aug 12, and d Aug 13-Sep 11. All the patterns are anomalies with respect to the summer mean over the 40 years. The positive contours are in red and the negative in blue. Vectors with the wind speed greater than $2 \mathrm{~m} \mathrm{~s}^{-1}$ are drawn. The red dashed line represents the cross-section used in Figs. 3, 4, PC time series $\mathrm{mm}$ day $\left.^{-1}\right)$, lower-tropospheric (May 15-September 11): a May 5, 8 and 9. e The corresponding (a) MAY 15-JUN 13

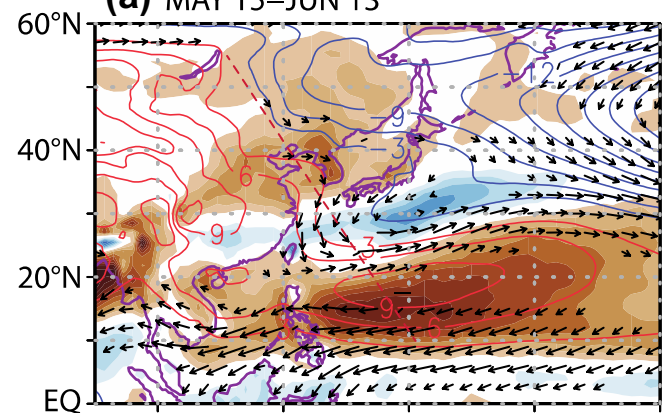

(c) JUL 14-AUG 12

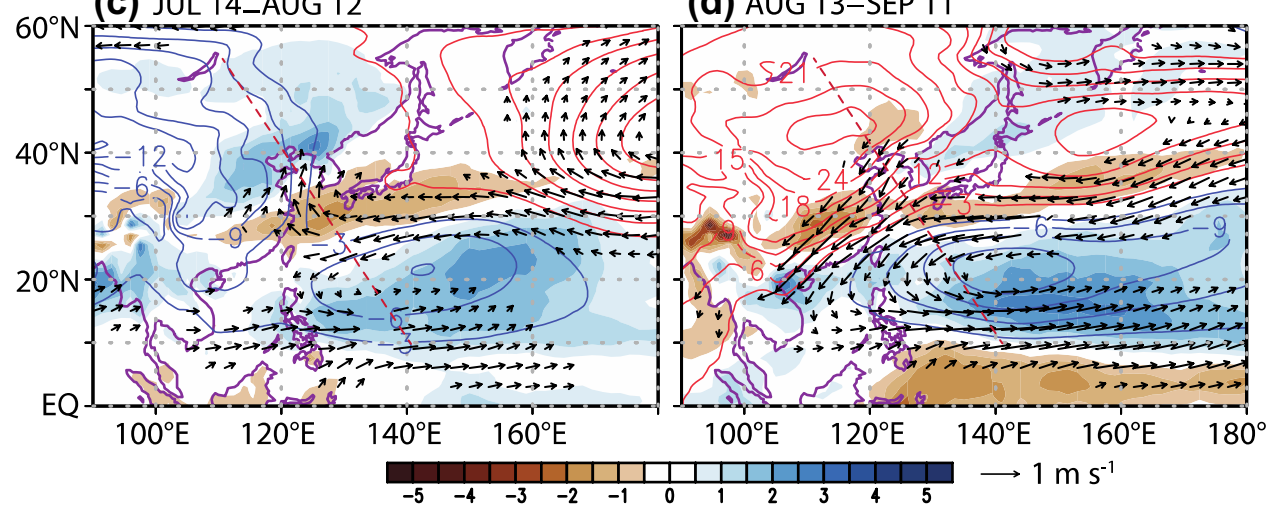

(b) JUN 14 JUL 13

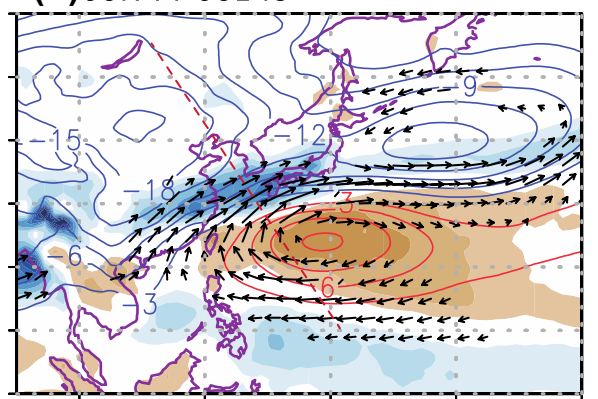

(d) AUG 13-SEP 11

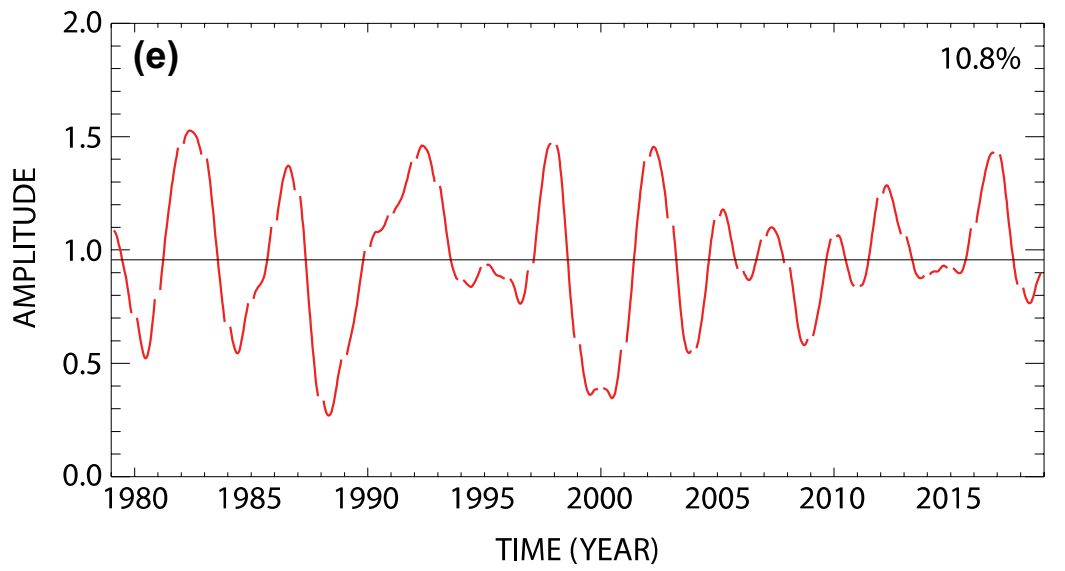

conducted in CSEOF space (Kim 2017). Let us consider another variable, $P(r, t)$, which can be decomposed as

$P(r, t)=\sum_{n} C_{n}(r, t) P_{n}(t)$.

$\frac{1}{M} \sum_{t=1}^{M} T_{n}(t) T_{m}(t)=\lambda_{n} \delta_{n m}$,

where $N$ is the number of spatial points, $M$ is the number of temporal points, $\delta_{n m}$ is the Kronecker delta, and $\lambda_{n}$, called eigenvalue, represents the variance of $T_{n}(t)$. Thus, CSEOF analysis decomposes data into mutually orthogonal patterns of evolution, of which the PC time series are mutually uncorrelated.

In order to make two or more variables to be physically consistent with each other, regression analysis is
Then, the PC time series of the so-called "target variable", $T_{n}(t)$, is written as a regression equation in terms of the PC time series of the "predictor variable", $P_{m}(t)$ :

$T_{n}(t)=\sum_{m=1}^{M} \alpha_{m}^{(n)} P_{m}(t)+\varepsilon^{(n)}(t), \quad n=1,2, \ldots$,

where $M$ is the number of predictor time series used for multivariate regression, $\alpha_{m}^{(n)}$ are regression coefficients, and $\varepsilon^{(n)}(t)$ is regression error time series. Then, the so-called "regressed" CSLVs are determined as 
Fig. 2 The patterns of precipitation (shading; $\mathrm{mm}_{\text {day }}{ }^{-1}$ ), lower-tropospheric (1000$850 \mathrm{hPa}$ ) geopotential height (contoured at $3 \mathrm{~m}$ interval) and wind (vectors) over East Asia during summer (May 15-September 11) associated with regional warming: a May 15-Jun 13, b Jun 14-Jul 13, c Jul 14-Aug 12, and d Aug 13-Sep 11. All the patterns are anomalies. The positive contours are in red and the negative in blue. Vectors with the wind speed greater than $0.3 \mathrm{~m} \mathrm{~s}^{-1}$ are drawn. e The corresponding PC time series (red curve) and its linear trend (blue dashed line), with 3 warmest years (red dots) and 3 coolest years (blue dots)

\section{(a) MAY 15-JUN 13}

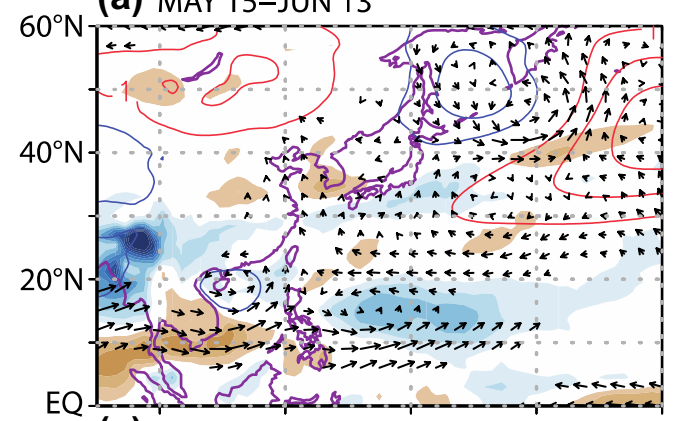

(c) JUL 14-AUG 12
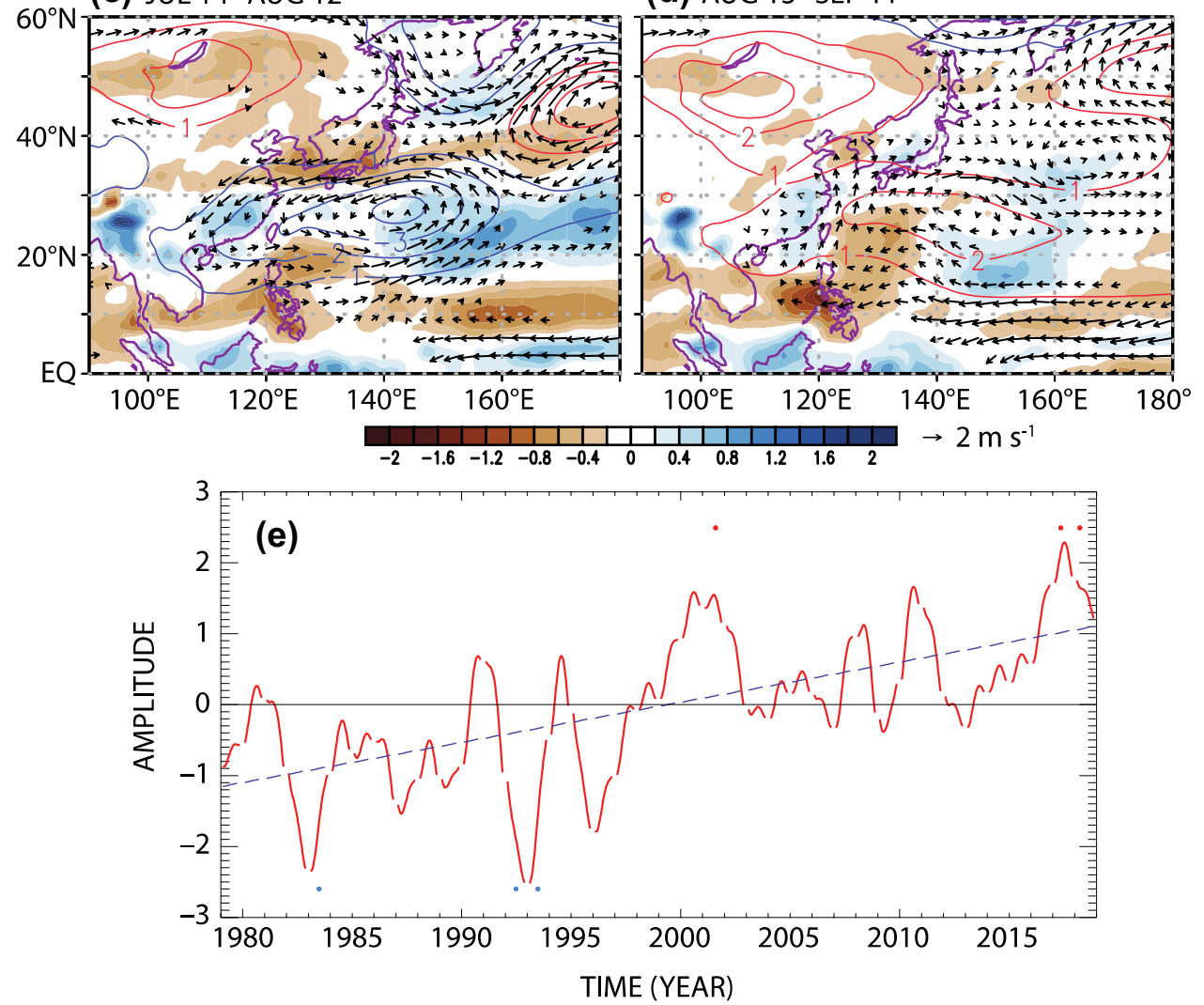

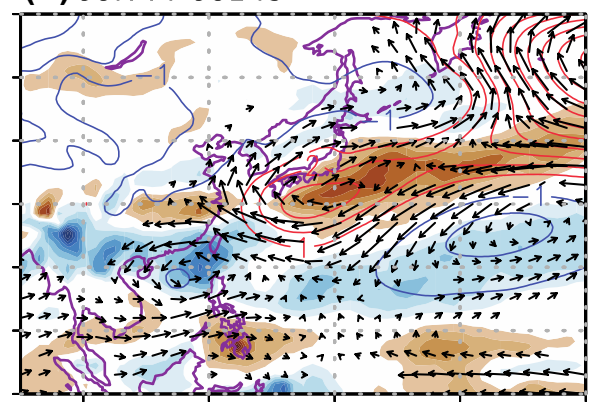

(d) AUG 13-SEP 11 (b) JUN 14-JUL 13
$C_{n}^{(\mathrm{reg})}(r, t)=\sum_{m=1}^{M} \alpha_{m}^{(n)} C_{m}(r, t)$.

Then, the predictor variable can be rewritten as

$P(r, t)=\sum_{m} C_{m}(r, t) P_{m}(t)=\sum_{n} C_{n}^{(\mathrm{reg})}(r, t) T_{n}(t)$.

Thus, the target and the predictor variables are written together as

$\{T(r, t), P(r, t)\}=\sum_{n}\left\{B_{n}(r, t), C_{n}^{(\mathrm{reg})}(r, t)\right\} T_{n}(t)$.

Thus, the CSLVs of the target variable, $B_{n}(r, t)$, and those of the predictor variable, $C_{n}^{(\mathrm{reg})}(r, t)$, are governed by the same
PC time series $T_{n}(t)$, and are considered to be physically consistent with each other.

This procedure can be repeated for other predictor variables. As a result of regression analysis in CSEOF space, entire variables can be written as

$\operatorname{Data}(r, t)=\sum_{n}\left\{B(r, t), C_{n}^{(\mathrm{reg})}(r, t), D_{n}^{(\mathrm{reg})}(r, t), \ldots\right\} T_{n}(t)$,

then, the terms in curly braces are considered physically consistent and depict multi-faceted evolution patterns of a physical process for each $n$. Surface air temperature is used as the target variable for extracting the warming mode. Then, the first mode $(n=1)$ depicts the seasonal cycle of summer 
(a) PRE

PRCP \& W

(b) POST
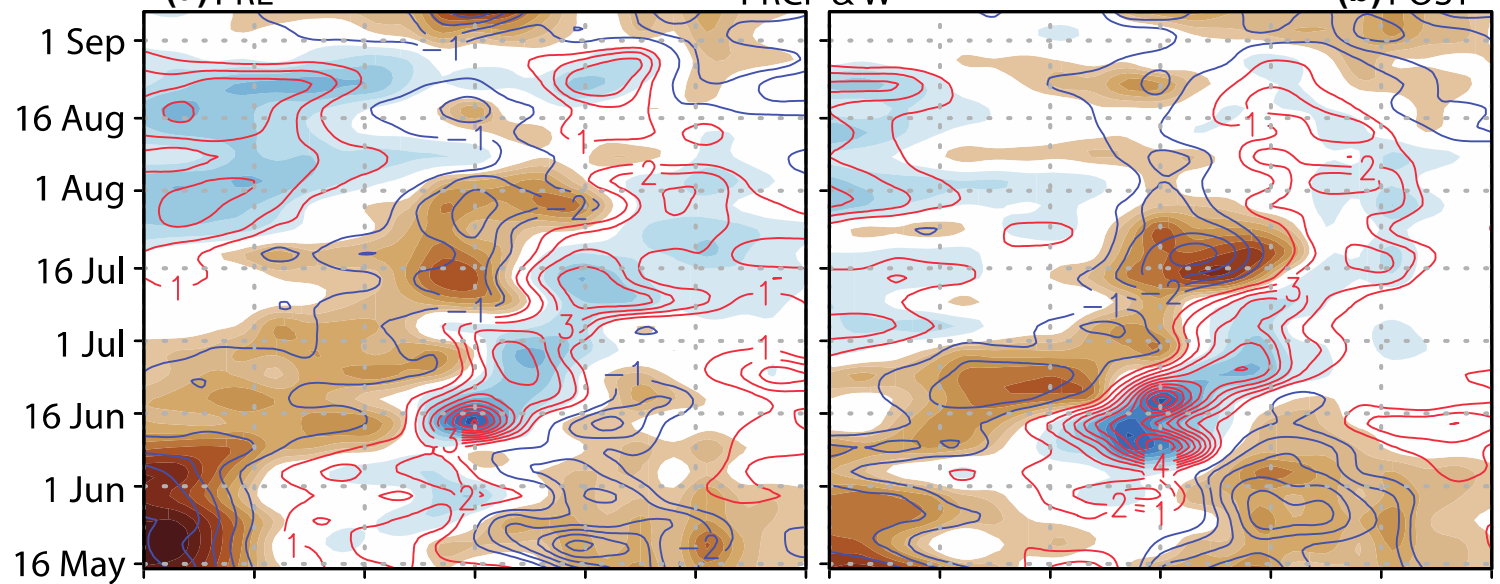

(c) PRE

$\mathrm{PRCP}, \mathrm{Q}$ CNV \& W CNV

(d) POST

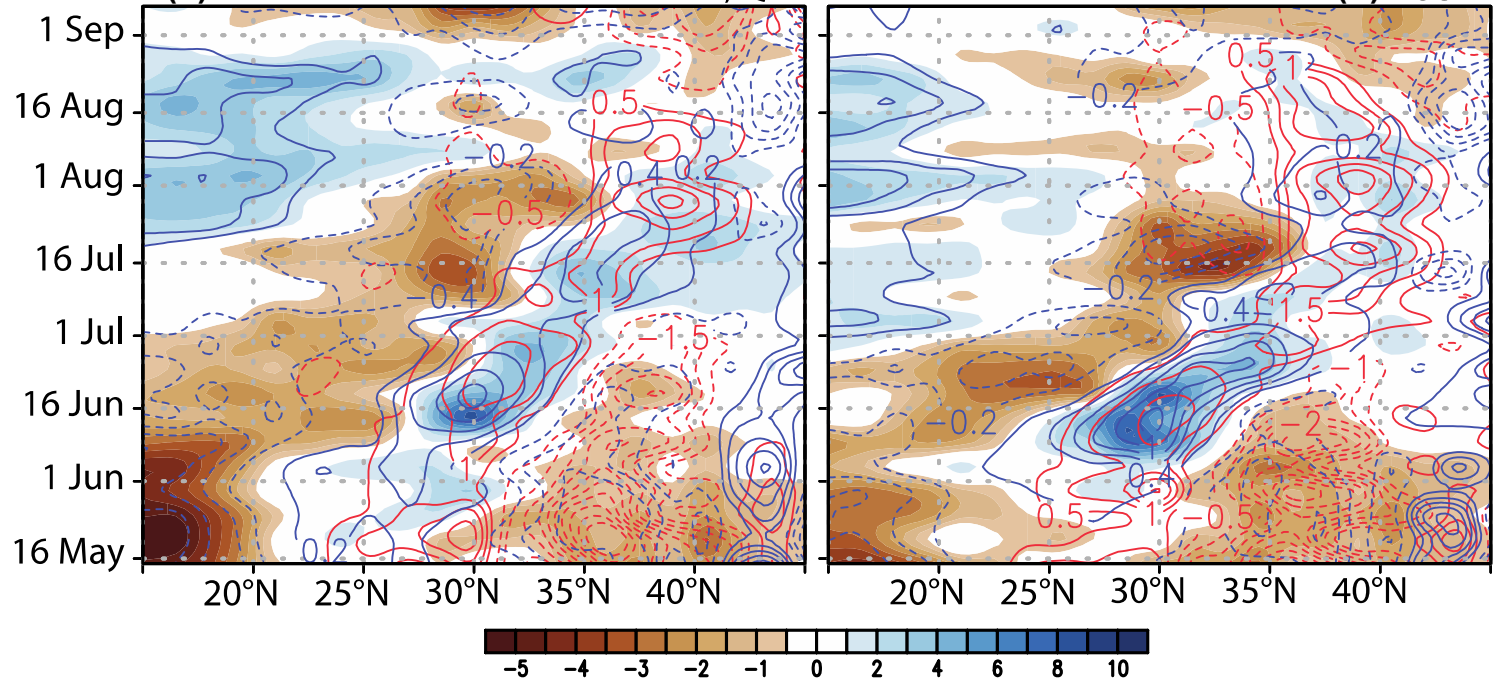

Fig. 3 The evolution of the seasonal cycle of precipitation (shading in units of $\mathrm{mm} \mathrm{day}^{-1}$ ) together with $\mathbf{a}, \mathbf{b}$ vertical velocity (red contours in units of $10^{-4} \mathrm{~Pa} \mathrm{~s}^{-1}$ ), and $\mathbf{c}, \mathbf{d}$ convergence of $500-\mathrm{hPa}$ $\mathrm{Q}$-vectors (red contour at the interval of $5 \times 10^{-13} \mathrm{~m}^{-2} \mathrm{~s}^{-1}$ ) and lowertropospheric $(1000-500 \mathrm{hPa})$ wind (blue contours at the interval of

precipitation, and the second mode $(n=2)$ represents the evolution associated with warming over the study domain.

\section{Results}

In this study, data from May 15 to September 11 (120 days) each year from 1979 to 2018 (40 years) are used to investigate summertime variability in East Asia. Therefore, $d=24$ pentads (120 days), and the total record length is 960 points (24 pentads $\times 40$ years). By conducting regression analysis for the first two CSEOF modes, the entire evolution patterns associated with the seasonal cycle and the warming mode are identified. $\left.2 \times 10^{-7} \mathrm{~s}^{-1}\right)$ along the cross section (see Fig. 1) joining $\left(139.5^{\circ} \mathrm{E}\right.$, $\left.10.5^{\circ} \mathrm{N}\right)$ and $\left(109.5^{\circ} \mathrm{E}, 55.5^{\circ} \mathrm{N}\right)$. All the patterns are anomalies. The left panels represent the pre-warming period and the right panels the post-warming period

Figure 1 shows the seasonal cycle of precipitation over the East Asian domain at the four characteristic stages of evolution: (a) initiation, (b) maturity, (c) transition, and (d) termination (Lim et al. 2002). In the initiation stage, precipitation begins to increase in the low-latitude regions including the Indochina Peninsula and Southeast China. In the mature stage, active moisture transport is seen along the eastern coast of the Asian continent, marking the onset of long spell of precipitation in East Asian countries including China, Japan, and Korea. The transition period exhibits the southward migration of the jet axis and weakening of the westerly jet along the rainband. During this period, monsoonal circulation begins to be reversed due to the establishment of low pressure anomaly over the ocean. In the termination stage, monsoon circulation is completely reversed 

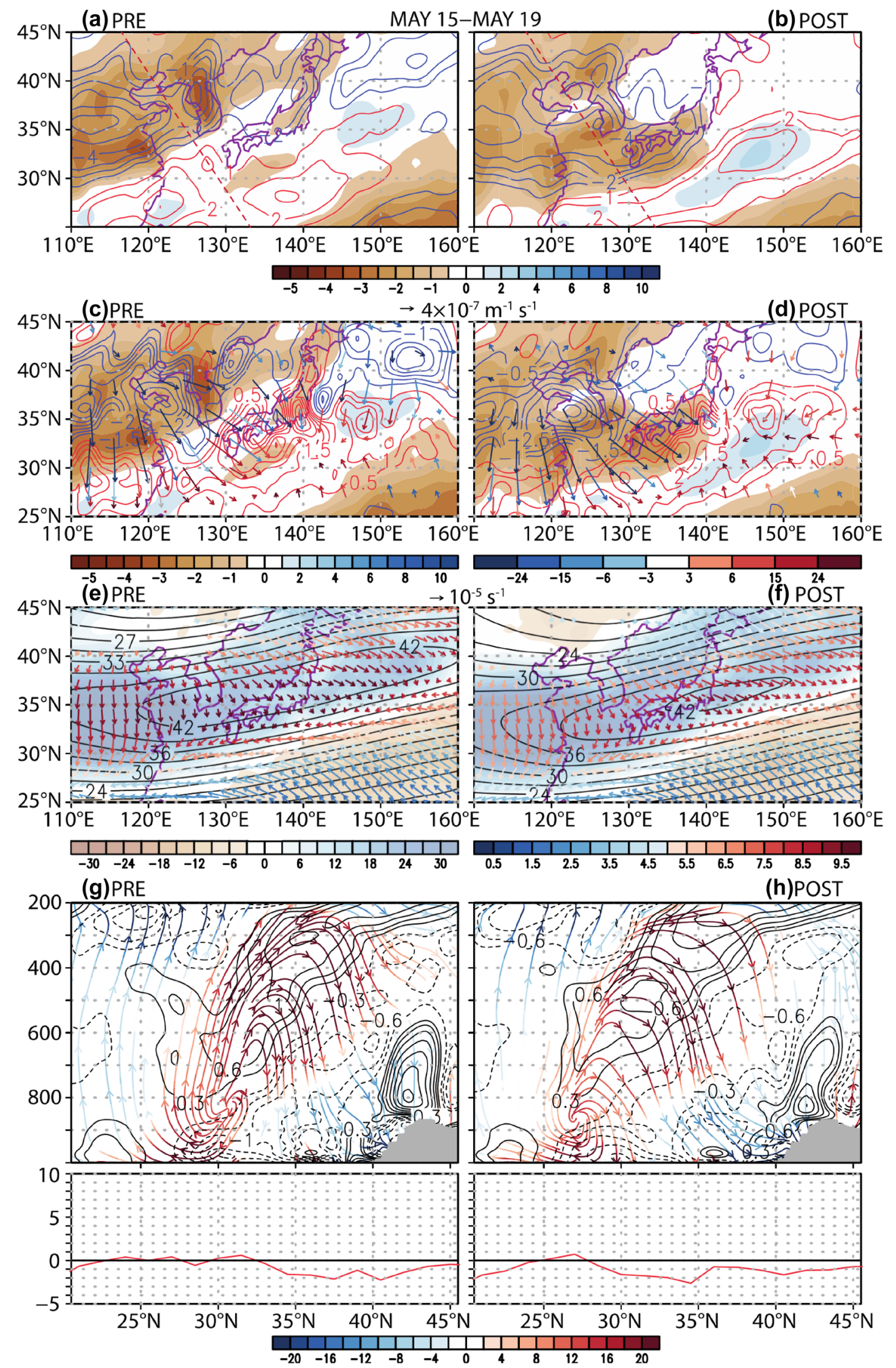
४Fig. 4 Anomalous patterns of (a, b) precipitation (shading; $\left.\mathrm{mm} \mathrm{day}{ }^{-1}\right)$ and 500-hPa vertical velocity ( $-\omega$, contour; $\left.10^{-4} \mathrm{~Pa} \mathrm{~s}^{-1}\right)$, c, d precipitation (shading; left color bar), 500-hPa Q-vectors (vectors; $10^{-7} \mathrm{~m}^{-1} \mathrm{~s}^{-1}$ ), Q-vector convergence (contours; $10^{-12} \mathrm{~m}^{-2}$ $\mathrm{s}^{-1}$ ), and vertical velocity (color of vectors; $10^{-4} \mathrm{~Pa} \mathrm{~s}^{-1}$; right color bar), e, f $500-\mathrm{hPa} \frac{1}{2}\left|\nabla_{h} T\right| D \cos (2 \eta)$ (shading; $10^{-12} \mathrm{~K} \mathrm{~m}^{-1} \mathrm{~s}^{-1}$; left color bar), $D\left(\sin 2 \eta,-\cos 2 \eta\right.$ ) (vector; $\left.10^{-6} \mathrm{~s}^{-1}\right),\left|\nabla_{h} T\right|$ (color of vector; $10^{-6} \mathrm{~K} \mathrm{~m}^{-1}$; right color bar), and $200-\mathrm{hPa}$ wind speed (contours; $\mathrm{m} \mathrm{s}^{-1}$ ), $\mathbf{g}, \mathbf{h}$ ageostrophic circulation (streamlines) with the magnitude of $\frac{1}{2}\left|\nabla_{h} T\right| D \cos (2 \eta)$ in color, wind convergence (contours; $10^{-6}$ $\mathrm{s}^{-1}$ ), and precipitation (red curve; $\mathrm{mm} \mathrm{day}^{-1}$ ) along the cross section (see dashed lines in $\mathbf{a}, \mathbf{b}, \mathbf{e}$, and f) joining $\left(139.5^{\circ} \mathrm{E}, 10.5^{\circ} \mathrm{N}\right)$ and $\left(109.5^{\circ} \mathrm{E}, 55.5^{\circ} \mathrm{N}\right)$ in the initiation stage of the East Asian summer monsoon (May 15-19). Positive contours in a-d are in red and negative in blue. The left column represents the pre-warming period and the right column the post-warming period

with a southward moisture transport anomaly along the eastern side of the continent.

The corresponding PC time series shows that the amplitude of the seasonal cycle of precipitation varies by about $\pm 50 \%$ during 1979-2018. While convective precipitation explains a larger fraction of total precipitation over the domain (see supplementary Figs. S2a and S2b), large-scale precipitation is a major source of variability for the monsoon precipitation band (see Figs. S2c and S2d).

Figure 2 shows the warming mode and the corresponding PC time series. As can be seen in the figure, significant change is seen in terms of low-level tropospheric circulation and precipitation due to warming. The linear fit to the PC time series indicates that the magnitude of warming has increased by $\sim 2.3$ during the past 40 years; while the PC time series shows both anthropogenic and natural causes of regional warming (Lean and Rind 2008; Liu et al. 2013; Zhang 2015), the linear trend may primarily reflect the manmade change. Multiplying this magnitude change with the CSEOF loading vector, we see that the effect of warming on summer precipitation in East Asia amounts to a significant fraction of the seasonal variation of precipitation.

In the following, evolution of variables during the monsoon period will be contrasted between the pre-warming and post-warming background conditions. The pre-warming and post-warming periods should be understood as the period of weak regional warming and that of strong regional warming, respectively. For this, seasonal evolution of precipitation in the pre-warming (post-warming) condition is defined by adding the regional warming mode (Fig. 2a-d) multiplied by the 1979 (2018) value of the linear trend in Fig. 2e. Thus, the regional warming mode represents the background change in which the seasonal cycle of precipitation evolves. Other variables in the pre-warming and post-warming conditions are defined in the same way. Other factors that can affect the East Asian monsoon are not taken into consideration in order to focus solely on the impact of regional warming.
The formation and evolution of monsoon rainband is an important scientific issue, since it essentially dictates the amount of rain at a specific region at a specific time of the year. Figure 3 shows precipitation along the path of monsoon evolution from $\left(139.5^{\circ} \mathrm{E}, 10.5^{\circ} \mathrm{N}\right)$ to $\left(109.5^{\circ} \mathrm{E}\right.$, $55.5^{\circ} \mathrm{N}$ ) (red dashed line in Fig. 1). Figure 3 demonstrates that monsoon climatology has changed significantly during the past 40 years due to regional warming. Much heavier rainfall is seen in June at $\sim 25^{\circ}-30^{\circ} \mathrm{N}$ (see Fig. 3a, b). On the other hand, rainfall has decreased significantly at $\sim 30^{\circ}-35^{\circ} \mathrm{N}$ followed by a substantial precipitation reduction starting from mid-July. The Changma front affecting the Korean peninsula is not established firmly in early July. Further, the secondary (late) Changma has significantly dwindled in late August (see Fig. 3a, b).

The evolution of precipitation matches well with the 500-hPa vertical (negative omega) velocity, which in turn is explained by the lower-tropospheric convergence of horizontal wind and 500-hPa Q-vectors. According to the continuity equation (mass conservation principle) in pressure coordinates, horizontal convergence of wind is related with the variation of vertical velocity with pressure:

$-\nabla_{h} \cdot \vec{v}=\frac{\partial \omega}{\partial p}$

Thus, positive wind convergence in the lower troposphere leads to an upward motion.

The Q-vectors are defined by

$\vec{Q}=-\frac{R}{p}\left(\frac{\partial \vec{v}_{g}}{\partial x} \cdot \nabla T, \frac{\partial \vec{v}_{g}}{\partial y} \cdot \nabla T\right)$,

and depicts essentially variation of thermal advection $\left(-\vec{v}_{g} \cdot \nabla T\right)$ due to the variation of geostrophic wind $\vec{v}_{g}$ in each direction. According to the quasi-geostrophic theory (Hoskins et al. 1978; Holton 2004), convergence of $\vec{Q}$ leads to an upward velocity. As can be seen in Fig. 3b, convergence of $\vec{Q}$ and that of lower-tropospheric wind explain reasonably the evolution of vertical velocity and precipitation.

In order to elaborate on the possible mechanisms of precipitation change due to regional warming, several thermodynamic quantities are compared between the pre-warming and the post-warming periods. Figure 4 shows the pattern of precipitation as well as those of other physical variables on May 15-May 19. At this early stage of the EASM, precipitation has generally increased over the continent and the western Pacific and decreased over southeast China and the southern Japan due to warming (see Fig. 4a, b). The patterns of vertical velocity are consistent with those of precipitation.

This is also reflected in the pattern of Q-vector convergence (Fig. 4c, d); slightly increased convergence and decreased divergence is seen over the western Pacific and 

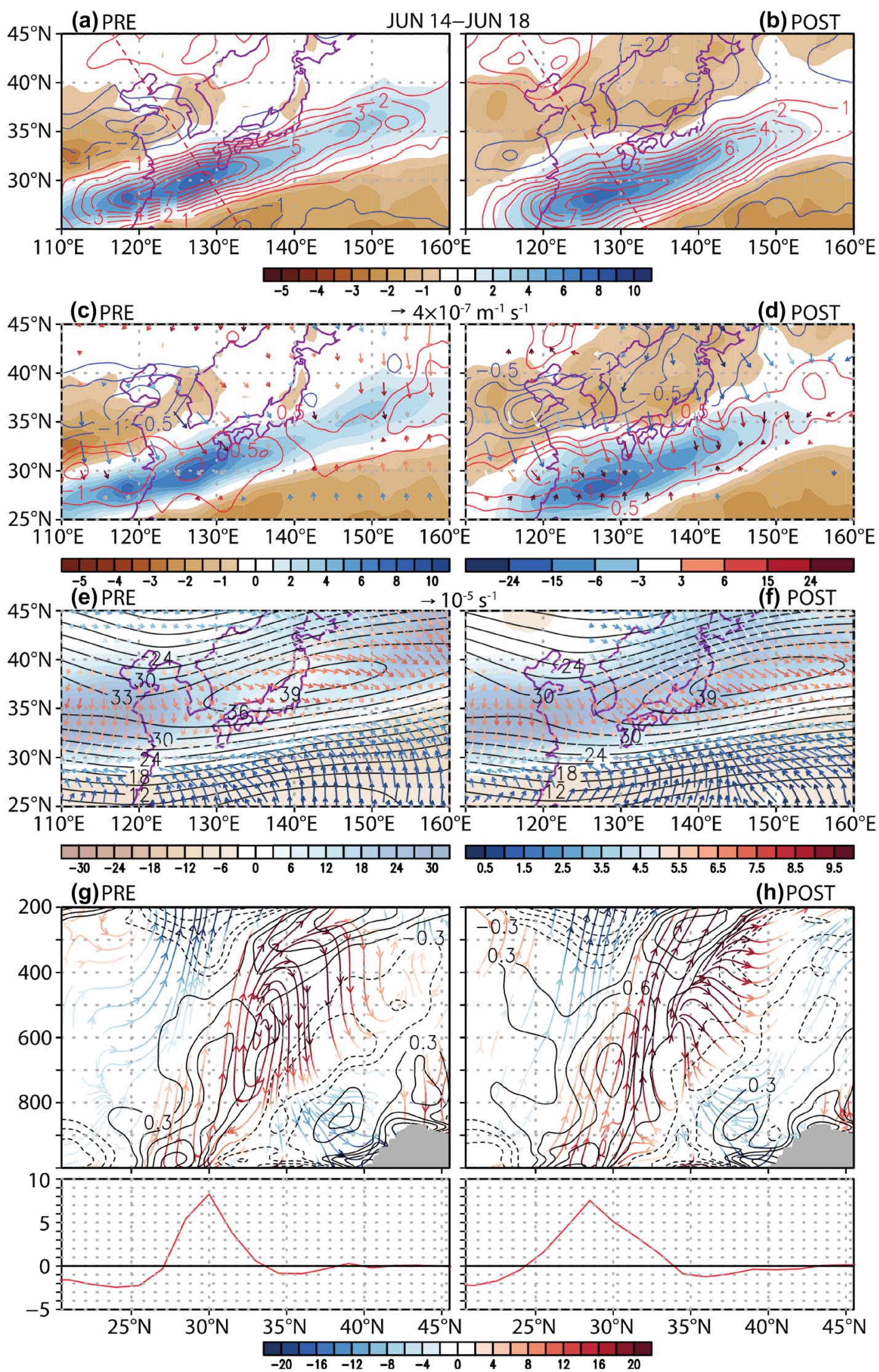

Fig. 5 Same as Fig. 4 except in the maturity stage of the East Asian monsoon (June 14-18) 
over the continent north of $\sim 30^{\circ} \mathrm{N}$, respectively. While the $\mathrm{Q}$-vector convergence is significant over the southern part of Japan in the post-warming period, downward motion is still dominant in this area (Fig. 4b, d).

From the thermodynamic energy equation, we obtain based on the quasi-geostrophic assumption (see "Appendix" for a full derivation)

$\frac{D_{g}}{D t}\left(\frac{R}{p}\left|\nabla_{h} T\right|\right)=\left[\left(\frac{R}{c_{p} p}\right) \nabla_{h} J_{0} \cdot \frac{\nabla_{h} T}{\left|\nabla_{h} T\right|}+\frac{R}{2 p}\left|\nabla_{h} T\right| D \cos (2 \eta)\right]$.

The left-hand side of (13) denotes the total change in horizontal temperature gradient (without sign) following the geostrophic motion. The right-hand side of (13) represents the contribution of diabatic/adiabatic heating $J_{0}$ (first term) and deformation $D$ in the production of horizontal temperature gradient. Figure $4 \mathrm{e}$ and $\mathrm{f}$ show the effect of deformation in terms of the magnitude of $D$ (length of vectors), angle $2 \eta$ as a vector $(\sin 2 \eta,-\cos 2 \eta)$, and the magnitude of horizontal temperature gradient $\left|\nabla_{h} T\right|$ (color of vectors) at $500 \mathrm{hPa}$ in comparison with the 200-hPa wind speed (black contours). Thus, if $2 \eta=0(2 \eta=\pi)$, the direction of vector is southward (northward), whereas vector points eastward (westward) for $2 \eta=\pi / 2(2 \eta=-\pi / 2)$. We will call $\frac{1}{2}\left|\nabla_{h} T\right| D \cos (2 \eta)$ the frontogenetic function. The sign of the frontogenetic function is solely determined by $\cos (2 \eta)$, which is expressed in terms of background shading in Fig. 4e, f.

At the initiation stage of the EASM, the direction of deformation is generally parallel to temperature contours ( $2 \eta \rightarrow 0$; southward arrows) in the northern part of the domain. On the other hand, the direction of deformation tends to be perpendicular to temperature contours in the southern part ( $2 \eta \rightarrow \pi$; northward arrows). This implies that isotherms become denser, and as a result, geostrophic wind speed increases in the northern part of the domain. In the southern part, the situation is opposite. This demarcation is a sign of frontogenesis, and develops slightly to the south of the 200-hPa jet speed maximum in agreement with earlier studies (Horinouchi and Hayashi 2017; Horinouchi et al. 2019).

According to the theory of frontogenesis (Hoskins 1982; Holton 2004), the increased geostrophic wind speed due to the increased thermal gradient is accompanied by cross-frontal ageostrophic wind in the direction perpendicular to the geostrophic wind. According to the mass conservation principle, this ageostrophic wind produces vertical motion, leading to a secondary cross-frontal circulation. The vertical section along the line connecting $\left(139.5^{\circ} \mathrm{E}, 10.5^{\circ} \mathrm{N}\right)$ and $\left(109.5^{\circ} \mathrm{E}, 55.5^{\circ} \mathrm{N}\right)$ clearly shows ageostrophic meridional circulation cell with a rising motion to the south and a sinking motion to the north of the front (Fig. 4g, h). In the region with an upward motion, precipitation begins to increase, and precipitation deficit (with respect to the summer mean) is seen in the region of a downward motion.

Figure 5 shows precipitation in the mature stage of the EASM (June 14-18). A well-developed monsoon band and the convergence of $\mathrm{Q}$ vectors are clearly seen along the Kuroshio Current (Fig. 5c, d). The width of the monsoon precipitation band has increased and the region of Q-vector convergence has widened due to warming. Further, the arrival of the monsoon band in Japan has been slightly delayed (see e.g., Kitoh and Uchiyama 2006).

A comparison between Fig. 5e, $\mathrm{f}$ indicates that front is more strongly developed to the south of Korea and Japan under a warming condition; the frontogenetic function exhibits a higher value along $\sim 30^{\circ} \mathrm{N}$ under a warming condition (Fig. 5e, f). This implies that cross-frontal circulation has become stronger mainly due to increased deformation $D$ to the south of the maximum jet. As can be seen in Fig. $5 \mathrm{~g}$ and $\mathrm{h}$, monsoon front is more strongly developed (denser streamlines and darker colors), and its position is shifted by $\sim 2^{\circ}$ southward (see e.g., Kawase et al. 2009; Horinouchi et al. 2019). The upward branch of the ageostrophic circulation is wider, leading to a wider band of precipitation.

Figures 6 and 7 show the patterns of several key variables when the monsoon front is over the Kuroshio Current. Both surface convergence and vertical velocity are enhanced over the warm Kuroshio Current (Figs. 6a-c, 7a-c). Convergence of horizontal wind and vertical velocity are seen to increase remarkably in the troposphere due to warming (Figs. 6d, 7d). This is also reflected in the sharper ascension of the streamlines of the eastward motion along the Kuroshio Current (Figs. 6e, 7e).

It should be pointed out that precipitation is significantly enhanced only when the monsoon front is over the Kuroshio Current. This indicates that ocean-atmospheric interaction is a crucial element for the intensification of precipitation. It appears that the warming of the Kuroshio Current has increased convergence of horizontal wind and strengthened vertical velocity. This implies that the adiabatic/diabatic forcing term $J_{0}$ in the frontogenetic function (13) plays an important role in the strengthening of the monsoon front when the front is over the Kuroshio Current. As a result, precipitation is enhanced under the warming condition. As the monsoon front migrates further north, vertical velocity and surface wind convergence diminishes quickly.

Figure 8 shows precipitation in the transition phase of the EASM (Fig. 8a, b). Precipitation is dominant over the northern land areas, and significant precipitation deficit (with respect to the summer mean) is seen over the East China Sea. 


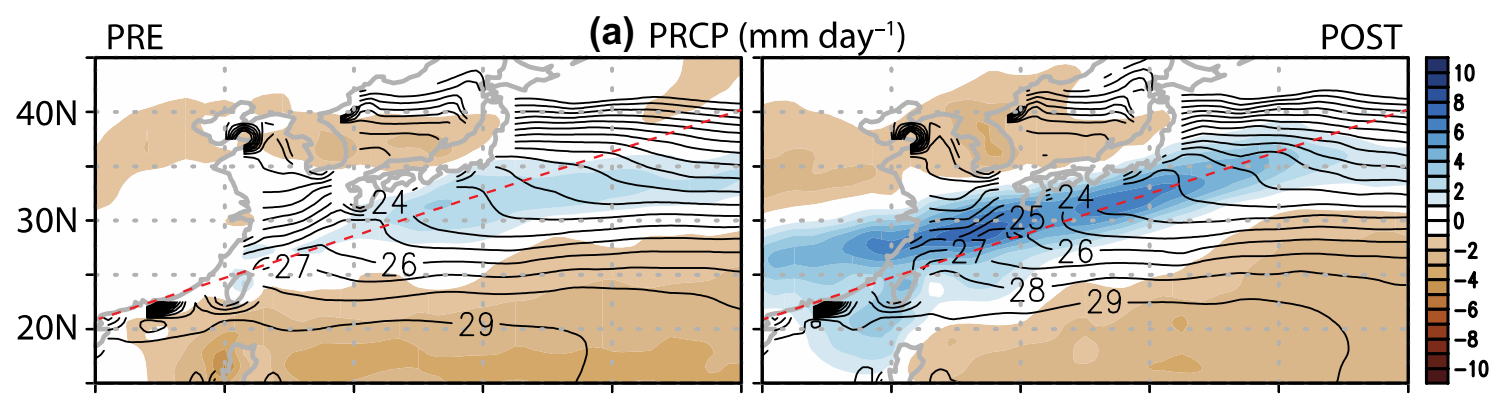

(b) $\operatorname{CNV}\left(\times 10^{-6} \mathrm{~s}^{-1}\right)$
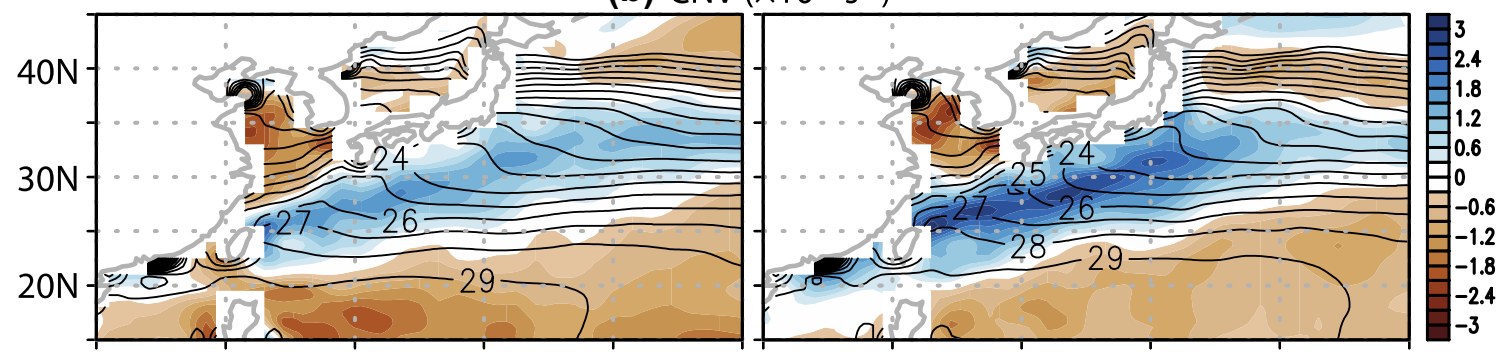

(c) $\mathrm{W}\left(\times 10^{-3} \mathrm{~Pa} \mathrm{~s}^{-1}\right)$
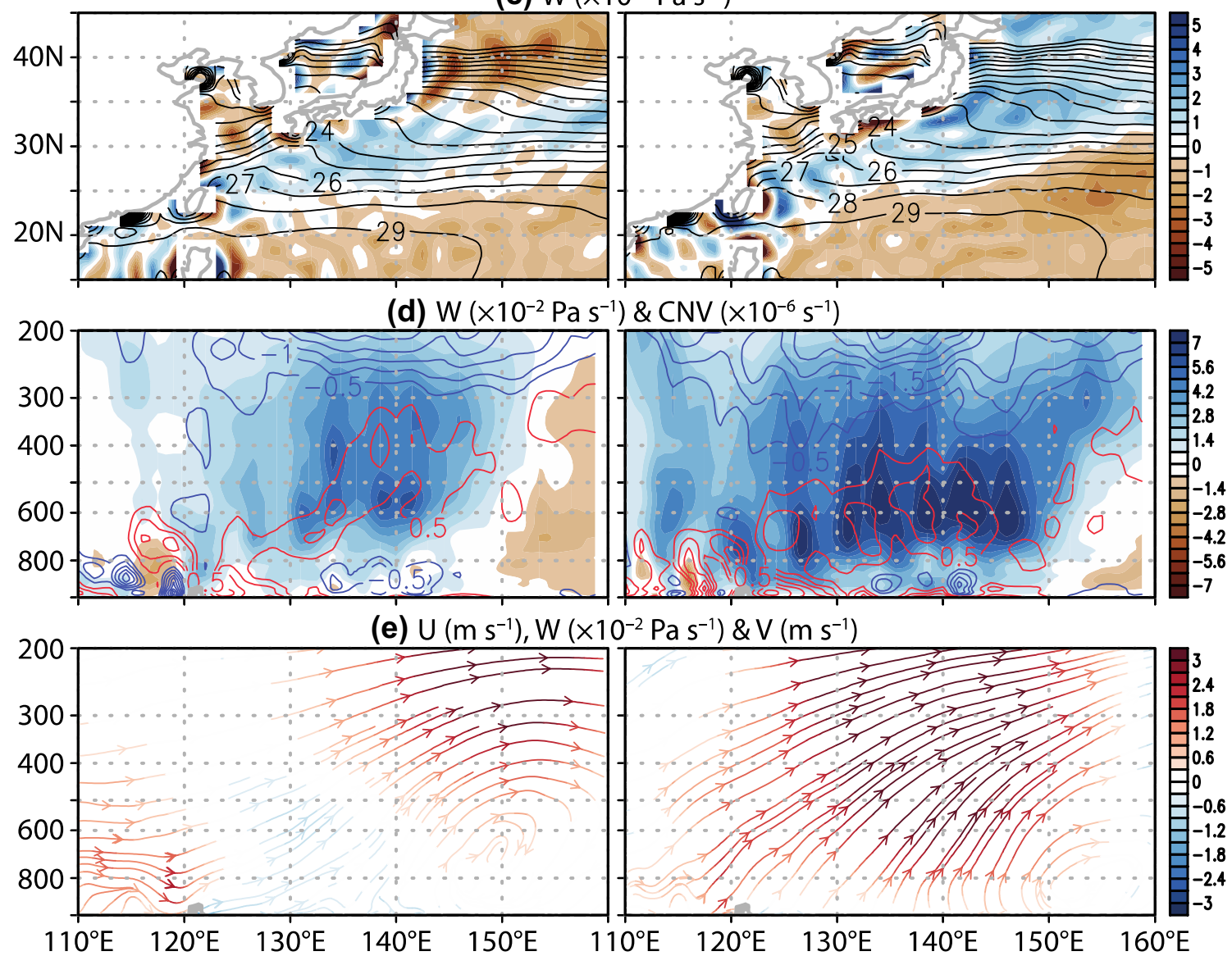

Fig. 6 The patterns of $\mathbf{a}-\mathbf{c}$ sea surface temperature (contour; ${ }^{\circ} \mathrm{C}$ ), $\mathbf{a}$ total precipitation (shade; $\mathrm{mm} \mathrm{day}^{-1}$ ), b $1000-\mathrm{hPa}$ wind convergence (shade; $10^{-6} \mathrm{~s}^{-1}$ ), c 1000 -hPa vertical velocity $\left(-\omega\right.$; shade; $10^{-3}$ $\left.\mathrm{Pa} \mathrm{s}^{-1}\right)$, d vertical cross section along $\left(110^{\circ} \mathrm{E}, 21^{\circ} \mathrm{N}\right)$ and $\left(159.5^{\circ} \mathrm{E}\right.$, $35^{\circ} \mathrm{N}$ ) (red dashed line in panel a) of vertical velocity (shade; $10^{-2}$ $\mathrm{Pa} \mathrm{s}^{-1}$ ) and wind convergence (contour; $10^{-6} \mathrm{~s}^{-1}$ ), and e streamlines of zonal $\left(\mathrm{m} \mathrm{s}^{-1}\right)$ and vertical velocity $\left(10^{-2} \mathrm{~Pa} \mathrm{~s}^{-1}\right)$ with the meridional component overlaid as color $\left(\mathrm{m} \mathrm{s}^{-1}\right)$ on Jun 9-13 


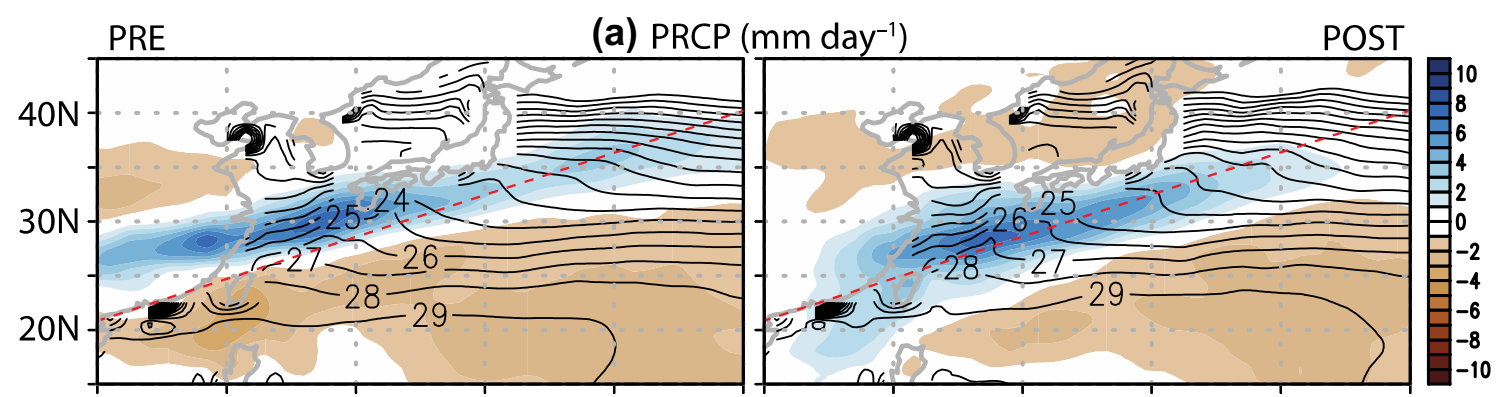

(b) $\mathrm{CNV}\left(\times 10^{-6} \mathrm{~s}^{-1}\right)$
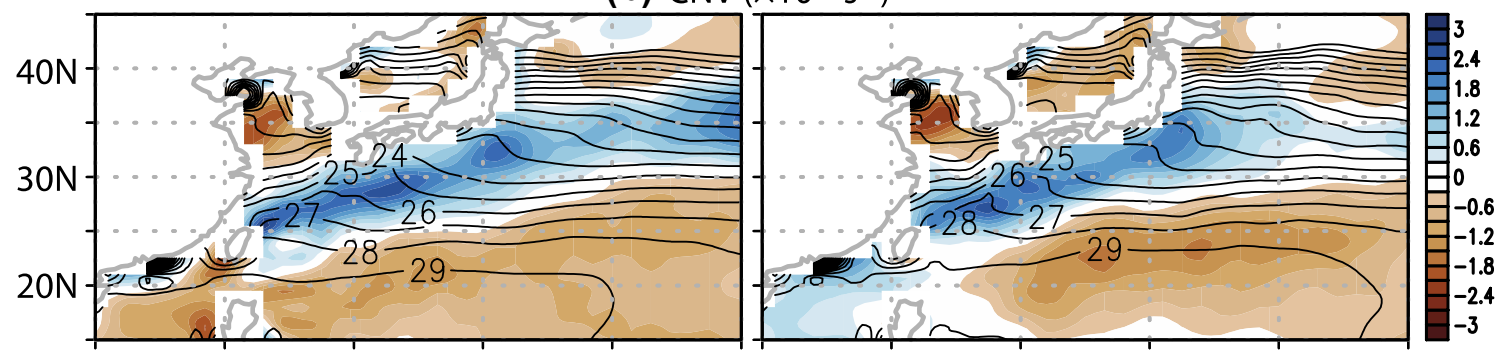

(c) $\mathrm{W}\left(\times 10^{-3} \mathrm{~Pa} \mathrm{~s}^{-1}\right)$
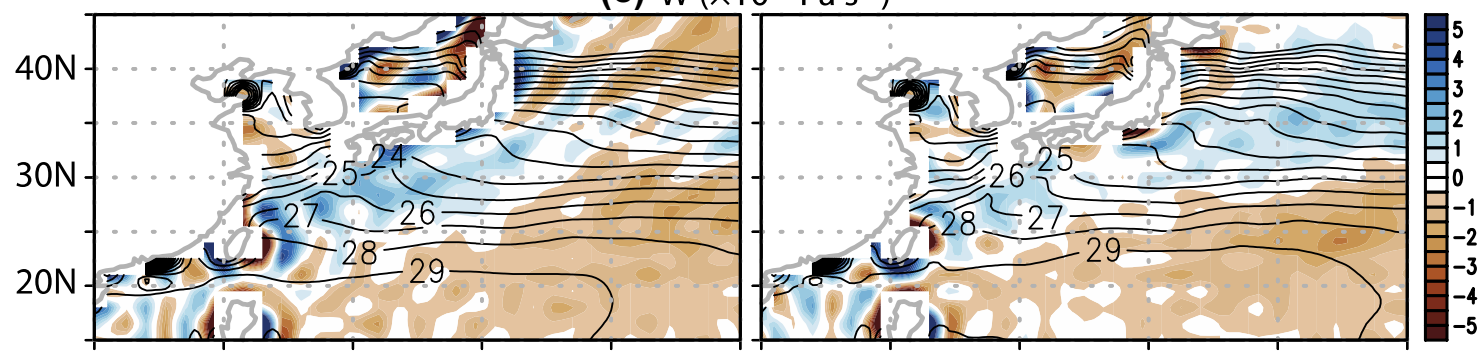

(d) $\mathrm{W}\left(\times 10^{-2} \mathrm{~Pa} \mathrm{~s}^{-1}\right) \& \mathrm{CNV}\left(\times 10^{-6} \mathrm{~s}^{-1}\right)$
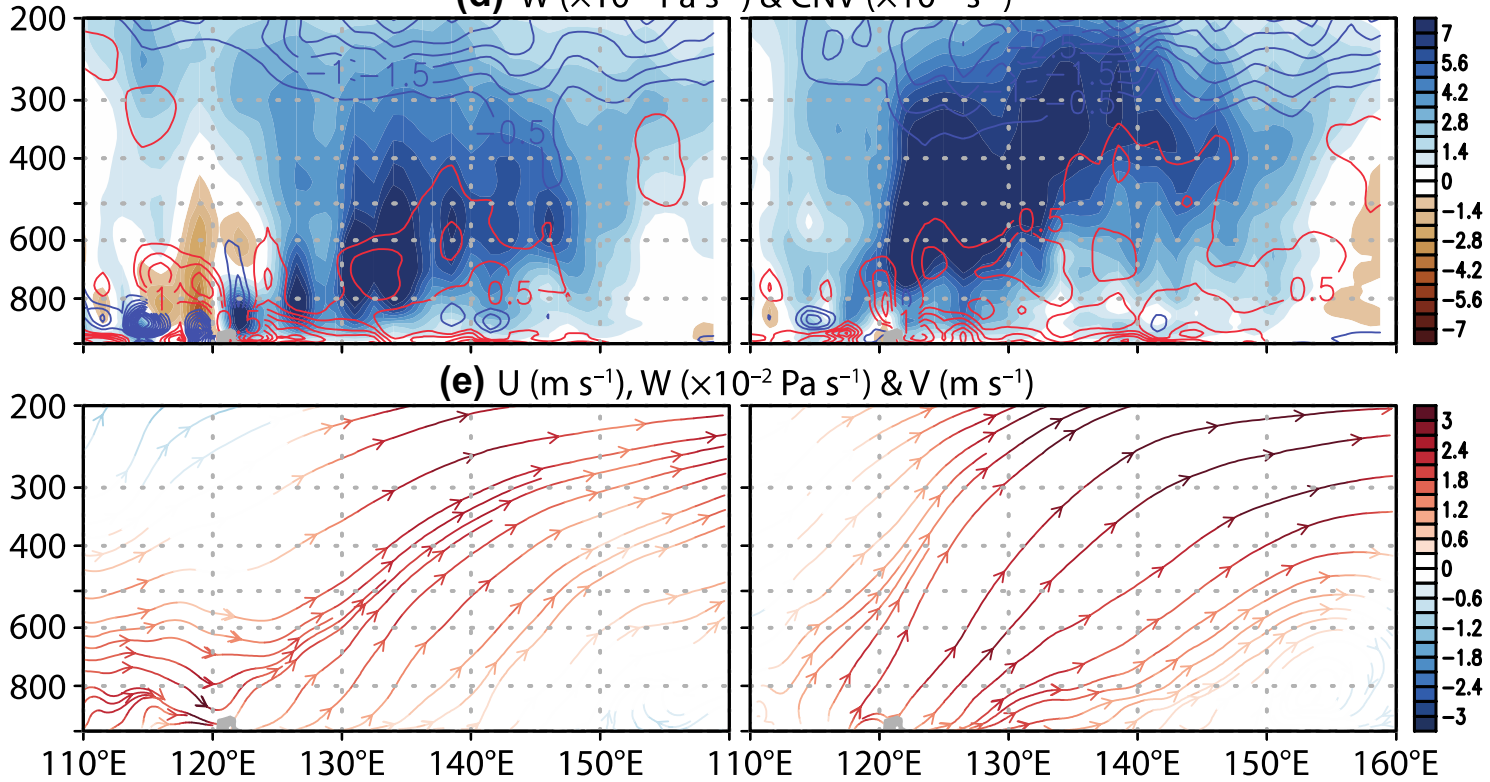

Fig. 7 Same as Fig. 6 except on Jun 14-18

The convergence pattern of $\mathrm{Q}$ vectors is marginally consistent with that of vertical velocity (Fig. 8a-d), suggesting that the vertical motion is induced by thermal advection as well as other mechanisms (such as convection from heat low).
In fact, a larger fraction of precipitation shown in Fig. 8a and $\mathrm{b}$ represents convective precipitation, the mechanism of which is only loosely connected with the frontogenesis (figure not shown). 

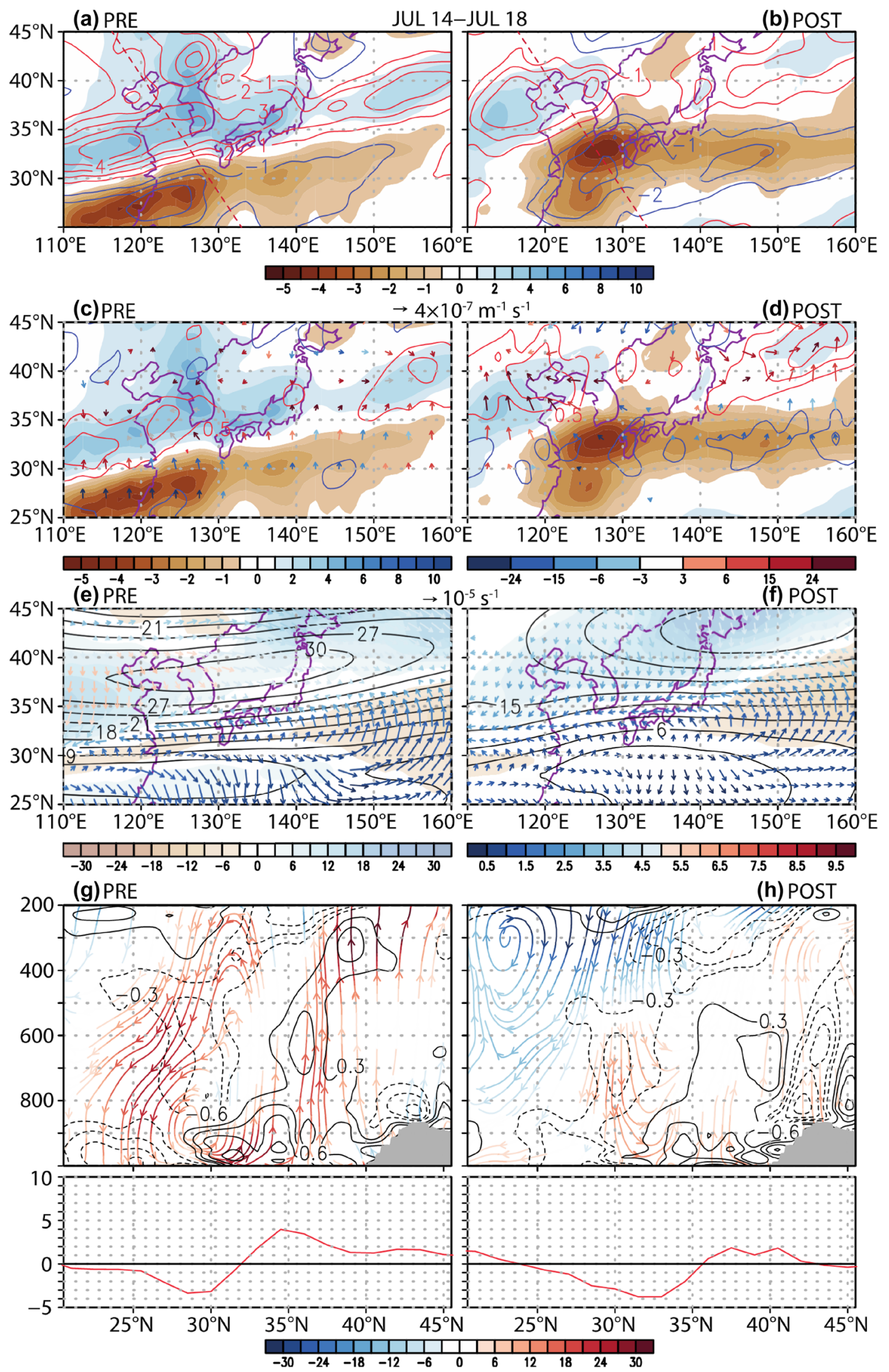

Fig. 8 Same as Fig. 4 except in the transition stage of the East Asian monsoon (July 14-18) 
In the pre-warming period, a narrow band of negative frontogenetic function runs northeastward in the middle of positive values to the west of $\sim 140^{\circ} \mathrm{E}$ (Fig. 8e), which results in two cells of secondary circulation (Fig. $8 \mathrm{~g}$ ). A broad region of upward motion and precipitation surplus is seen north of $\sim 32^{\circ} \mathrm{N}$ in the vertical section (Fig. $8 \mathrm{~g}$ ).

The frontal circulation has weakened significantly and its position has shifted northward by $\sim 5^{\circ}$ as a result of warming (Fig. 8f). This weakening is mainly due to weak temperature gradient both over the continent and the ocean. Also, the direction of deformation is not favorable for producing substantial temperature gradient. Due to the weak frontal circulation (Fig. 8h), precipitation has dwindled significantly to the north of the front (Fig. 8b).

Figure 9 shows the pattern of precipitation during the termination stage of the EASM (Fig. 9a, b). In the prewarming period, precipitation is strongly developed over the Korean peninsula; this secondary maximum of precipitation is called the second (or late) Changma in Korea. While strong convergence of $\mathrm{Q}$ vectors is seen to the west of the Korean peninsula, upward velocity is not so strong in the post-warming period (Fig. 9b, d). While the frontgenetic function is fairly strong to the west of the Korean peninsula (Fig. 9f), ageostrophic meridional circulation is disorganized and is limited to the upper troposphere (Fig. 9h). As can be seen, the location of front is shifted slightly northward in the post-warming period.

\section{Summary and discussion}

In the present study, we investigated the physical and dynamical mechanisms of monsoon precipitation change in East Asia associated with regional warming. In particular, we focused on the effect of warming in terms of the frontogenetic nature of the East Asian summer monsoon. It should first be noted that the precipitation patterns in Figs. 4, 5, 8 and 9 agree reasonably with the composite patterns of precipitation based on three coolest summers and three warmest summers in the record (see Fig. S4).

Figure 10 shows the evolution patterns of precipitation along the three meridional sections in the pre-warming and post-warming periods. Along $125^{\circ} \mathrm{E}$, precipitation has generally decreased throughout the summer due to warming except when the precipitation band is over the Kuroshio Current (Fig. 10a). To the north of $\sim 38^{\circ} \mathrm{N}$, both large-scale precipitation and convective precipitation contributes to this reduction. Between $\sim 26^{\circ}$ and $38^{\circ} \mathrm{N}$, weakening of largescale precipitation is primarily responsible for the reduction of precipitation. To the south of $\sim 26^{\circ} \mathrm{N}$, on the other hand, convective precipitation is largely responsible for the reduced precipitation. The increased precipitation over the
Kuroshio Current is caused mainly by the enhancement of large-scale precipitation.

Along $135^{\circ}$ E, precipitation is enhanced over the Kuroshio Current in early June (Fig. 10b). Otherwise, precipitation is generally reduced until near the end of summer. Again, large-scale precipitation is responsible for the precipitation reduction north of $\sim 38^{\circ} \mathrm{N}$, whereas convective precipitation is generally responsible for the reduced precipitation south of $\sim 28^{\circ} \mathrm{E}$.

Along $145^{\circ} \mathrm{E}$, increased precipitation is seen between $30^{\circ}$ and $40^{\circ} \mathrm{N}$ until the middle of June and then decreased precipitation until the rest of the summer (Fig. 10c). This pattern is induced largely by the change in large-scale precipitation. In the lower latitude, on the other hand, precipitation has increased since July 16 , and this change is primarily due to convective precipitation.

A notable change is seen in the frontogenesis of the East Asian monsoon as a result of warming. As summarized in Fig. 11, 200-hPa wind speed maximum migrates northward during the initiation and mature stages, and then southward during the transition and termination periods. The northward migration of the $200-\mathrm{hPa}$ jet speed maximum has become faster and the southward migration starts $\sim 2$ weeks earlier under the warming condition, particularly in the eastern part of the domain. This change in the meridional migration speed is due to the variation of 200-hPa geopotential as a result of regional warming (see Fig. S8 and the discussion therein). The monsoon front, which is developed slightly to the south of the maximum wind speed, also migrates with the maximum wind speed. This implies that the transition period develops $\sim 2$ weeks earlier under the warming condition.

The 200-hPa wind speed has increased in the initiation and the early mature stages, but slightly weakens since the late mature stage of the EASM. The increased wind speed is due to stronger thermal gradient in the initiation stage in particular, and is favorable for frontogenesis. The crossfrontal circulation, however, is not strongly established until the monsoon band reaches the Kuroshio Current. Under the warming condition, stronger wind convergence and vertical velocity are observed in the lower troposphere over the Kuroshio Current, resulting in stronger crossfrontal circulation and increased precipitation (primarily large-scale precipitation).

When the maximum wind is at its highest latitude $\left(\sim 35^{\circ}-40^{\circ} \mathrm{N}\right.$ during the latter part of the mature stage and the early part of the transition stage), cross-frontal circulation is fairly weak in the post-warming period; while deformation is not weak, temperature gradient is significantly reduced at the location of the front. As a result, precipitation is significantly reduced. It should also be noted that the front is shifted slightly northward upon regional warming. 

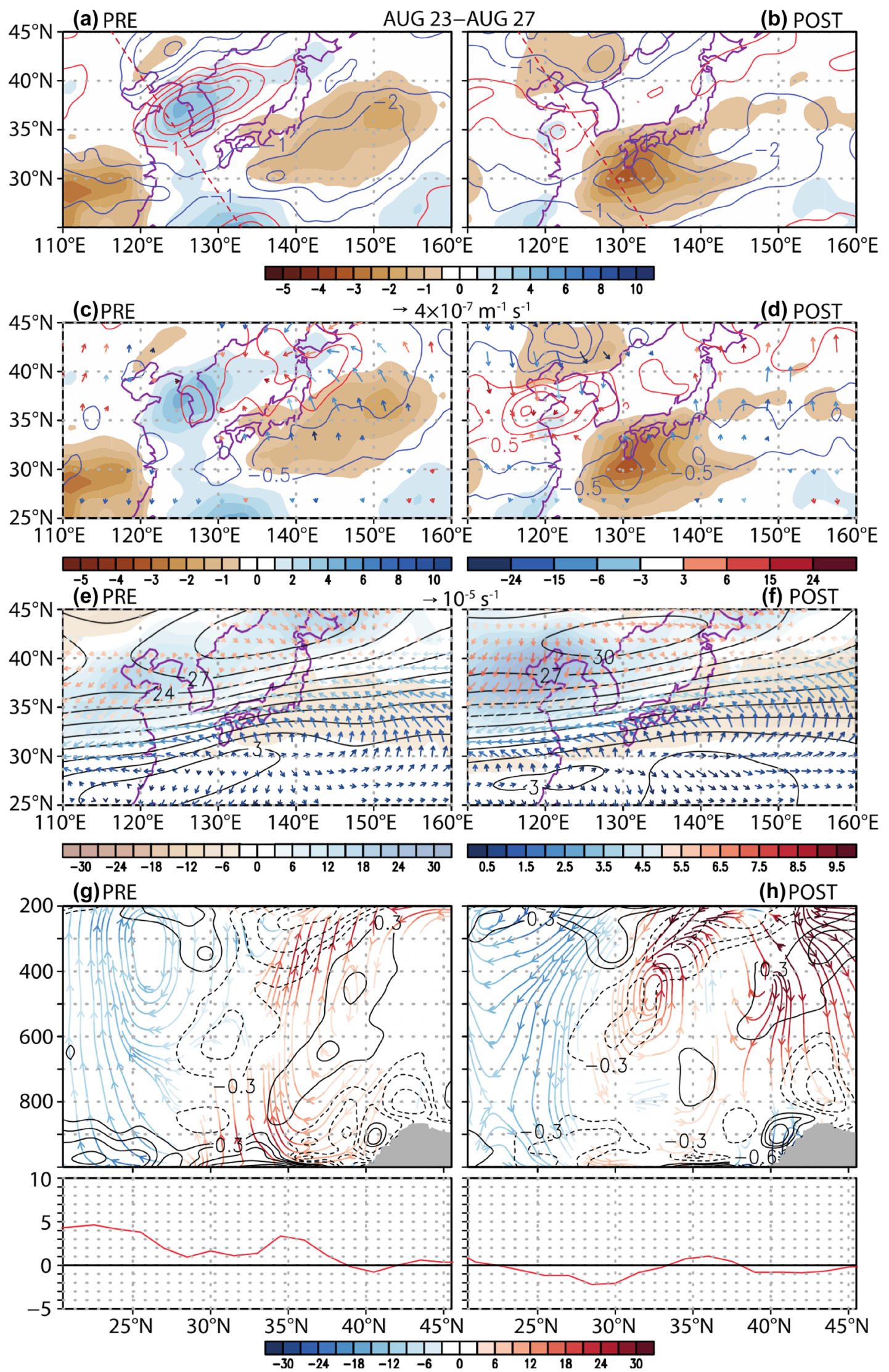

Fig. 9 Same as Fig. 4 except in the termination stage of the East Asian monsoon (August 23-27) 


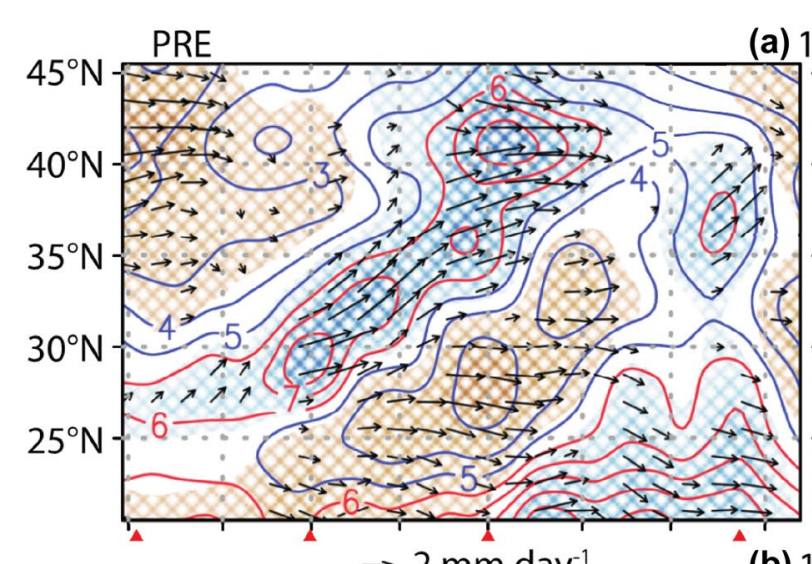

(a) $125^{\circ} \mathrm{E}$

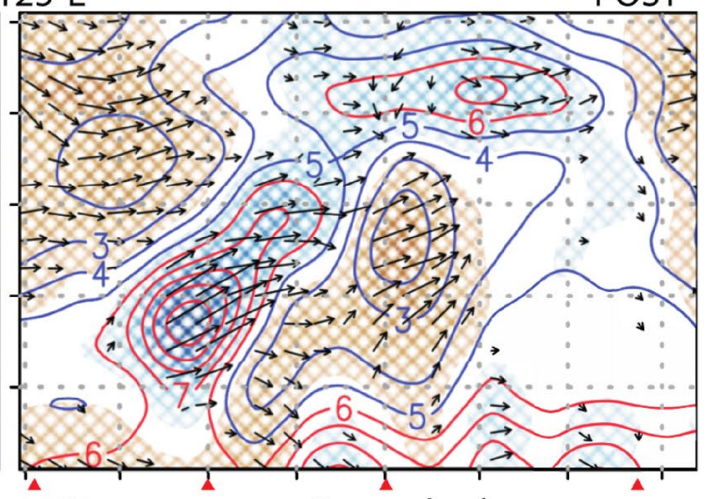

$\rightarrow 2 \mathrm{~mm}^{2}$ day $^{-1}$

(b) $135^{\circ} \mathrm{E}$ $\rightarrow 2 \mathrm{~mm}$ day $^{-1}$
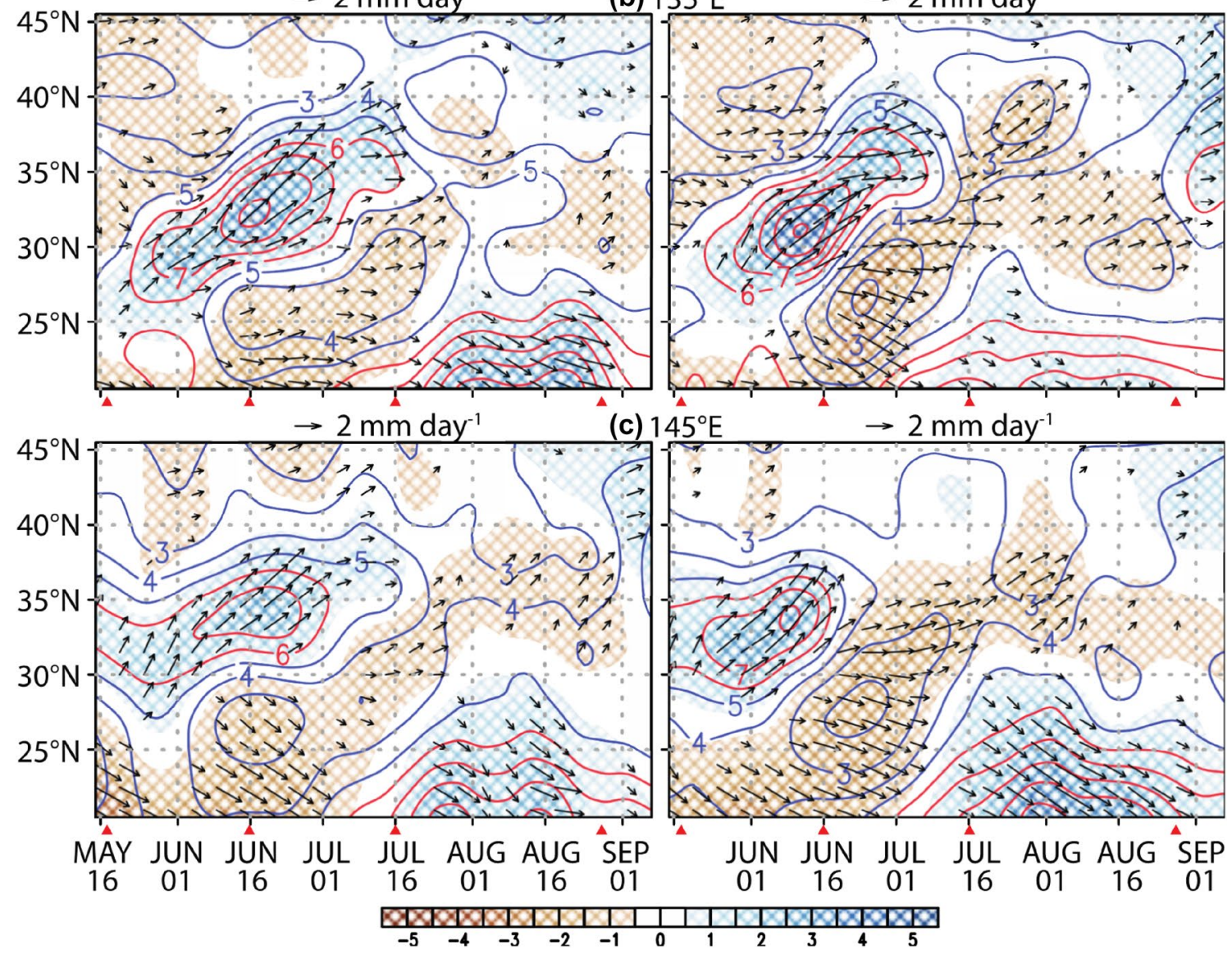

$145^{\circ} \mathrm{E}$ $\rightarrow 2 \mathrm{~mm}$ day $^{-1}$

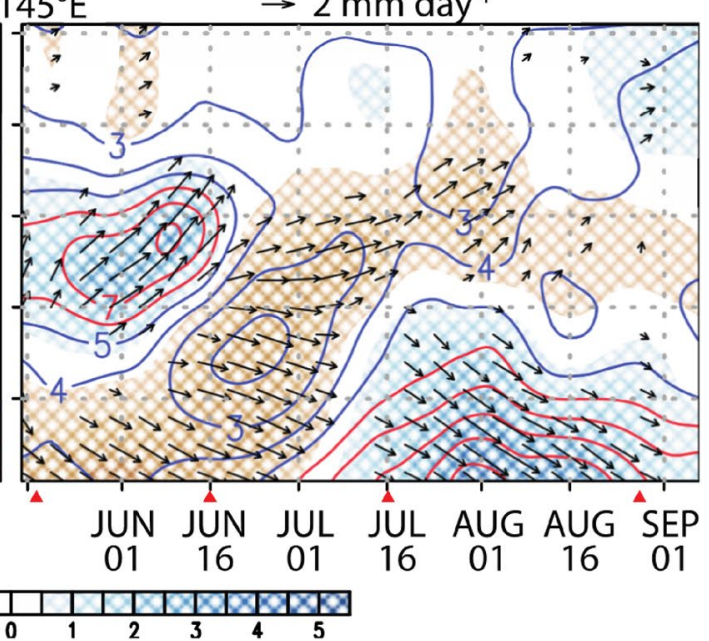

Fig. 10 Evolution of total precipitation (contours; $\mathrm{mm} \mathrm{day}{ }^{-1}$ ), anomalous precipitation from the summer mean (shade; $\mathrm{mm}_{\text {day }}{ }^{-1}$ ) and the contributions of large-scale precipitation and convective precipitation to precipitation anomalies (vectors) throughout the summer (May $15-$ September 11): a $125^{\circ} \mathrm{E}$, b $135^{\circ} \mathrm{E}$, and $\mathbf{c} 145^{\circ} \mathrm{E}$. The blue contours represent precipitation $\leq 5 \mathrm{~mm} \mathrm{day}^{-1}$, and the red contours $>5 \mathrm{~mm} \mathrm{day}^{-1}$. The contribution of large-scale precipitation and convective precipitation is measured in terms the angle of the vector,

As the EASM comes close to its termination, the front and jet move back southward, and the magnitude of deformation and temperature gradient increase again. Nevertheless, the amount of precipitation does not increase with the zero angle measured from the $x$ axis denotes equal contribution, positive angle denotes greater contribution by large-scale precipitation ( $45^{\circ}$ contribution by large-scale precipitation only), and negative angle greater contribution by convective precipitation $\left(-45^{\circ}\right.$ by convective precipitation only). The length of the vectors is proportional to the magnitude of the anomalous precipitation. The red triangles denote the four stages depicted in Figs. 4, 5, 8 and 9

compared to the maturity stage of the monsoon. This difference is attributed to the reduction of moisture supply by the low-level flow from the low-latitude region. 

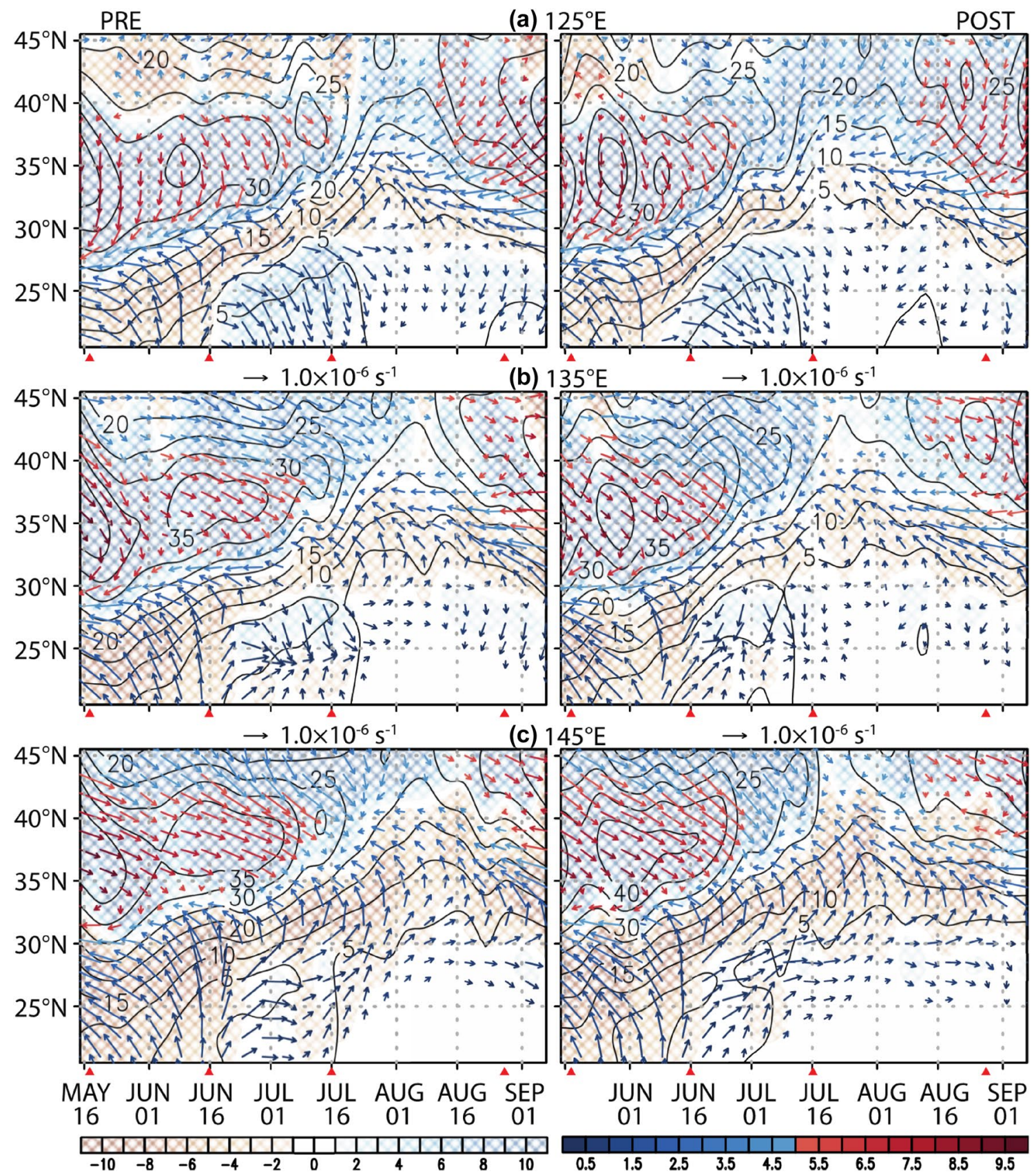

Fig. 11 Evolution of 500-hPa frontogenetic function $\left(10^{-12} \mathrm{~K} \mathrm{~m}^{-1}\right.$ $\mathrm{s}^{-1}$; shading; left color bar) together with the magnitude (length of vectors) and direction of deformation with respect to the direction of thermal gradient $(2 \eta$; angle measured counterclockwise from south), the magnitude of thermal gradient $\left(10^{-6} \mathrm{~s}^{-1}\right.$; color of vectors; right color bar), and 200-hPa wind speed (contours) throughout the summer (May $15-$ September 11): a $125^{\circ} \mathrm{E}, \mathbf{b} 135^{\circ} \mathrm{E}$, and c $145^{\circ} \mathrm{E}$. The red triangles denote the four stages depicted in Figs. 4, 5, 8 and 9

\section{Concluding remarks}

As demonstrated in this study, dynamic frontogenesis theory applies reasonably to summer precipitation in East Asia. Since the thermal capacity of land is much lower than that of the ocean, surface air temperature of mid-latitude land is higher than that of mid-latitude ocean while the difference is small in low-latitude. The difference in meridional temperature gradient between land and ocean causes zonally asymmetric jetstream. In summer, therefore, speed of jetstream increases as it passes the eastern shore of East Asia. This acceleration is accompanied 
by considerable deformation, which causes frontogenesis and frontolysis around the jet, thus generating secondary circulation across the frontal structure. Monsoon rainband is formed between the northern frontogenetic region and southern frontolytic region of the troposphere.

In conclusion, the East Asian monsoonal precipitation change due to regional warming is closely linked with the change in the location and magnitude of frontogenesis and the resulting cross-frontal ageostrophic circulation. In particular, change in the latitudinal location of the monsoon rainband is captured faithfully in terms of the frontogenetic function. Due to regional warming, the monsoon front has shifted slightly southward in early summer (maturity stage), but slightly northward in mid summer (transition stage). Thus, the seasonal migration of the monsoon front is more precipitous than in the past. Further, the cross-frontal circulation has generally weakened except in the maturity stage. These, in general, result in decreased amount of large-scale precipitation along the front. This trend is expected to continue as warming deepens in East Asia. While the frontal theory is reasonable in explaining the EASM precipitation pattern and its change due to global warming, such factors as rainband-warm current interaction and strong convection over land in late summer also contribute to the variation of precipitation.

Funding This work was funded by Korea National Research Foundation (Grant no. NRF-2017R1A2B4003930).

Open Access This article is licensed under a Creative Commons Attribution 4.0 International License, which permits use, sharing, adaptation, distribution and reproduction in any medium or format, as long as you give appropriate credit to the original author(s) and the source, provide a link to the Creative Commons licence, and indicate if changes were made. The images or other third party material in this article are included in the article's Creative Commons licence, unless indicated otherwise in a credit line to the material. If material is not included in the article's Creative Commons licence and your intended use is not permitted by statutory regulation or exceeds the permitted use, you will need to obtain permission directly from the copyright holder. To view a copy of this licence, visit http://creativecommons.org/licenses/by/4.0/.

\section{Appendix}

The thermodynamic energy equation is given by

$$
\frac{D_{g} T}{D t}=\frac{J}{c_{p}}+S_{p} \omega=\frac{J_{0}}{c_{p}}, \quad S_{p}=-T \frac{\partial \ln \theta}{\partial p} .
$$

Then, we have
$\frac{D_{g}}{D t}\left(\frac{\partial T}{\partial x}\right)=\frac{\partial}{\partial x}\left(\frac{D_{g} T}{D t}\right)-\frac{\partial u_{g}}{\partial x} \frac{\partial T}{\partial x}-\frac{\partial v_{g}}{\partial y} \frac{\partial T}{\partial y}$.

Multiplying (15) by $\partial T / \partial x$, we obtain

$\frac{D_{g}}{D t}\left(\frac{\partial T}{\partial x}\right)^{2}=2\left[\frac{1}{c_{p}} \frac{\partial J_{0}}{\partial x} \frac{\partial T}{\partial x}-\left(\frac{\partial T}{\partial x}\right)\left(\frac{\partial u_{g}}{\partial x} \frac{\partial T}{\partial x}+\frac{\partial v_{g}}{\partial x} \frac{\partial T}{\partial y}\right)\right]$.

Likewise,

$\frac{D_{g}}{D t}\left(\frac{\partial T}{\partial y}\right)^{2}=2\left[\frac{1}{c_{p}} \frac{\partial J_{0}}{\partial y} \frac{\partial T}{\partial y}-\left(\frac{\partial T}{\partial y}\right)\left(\frac{\partial u_{g}}{\partial y} \frac{\partial T}{\partial x}+\frac{\partial v_{g}}{\partial y} \frac{\partial T}{\partial y}\right)\right]$.

Therefore, we can write

$$
\begin{aligned}
\frac{D_{g}}{D t}\left|\nabla_{h} T\right|^{2}= & 2\left[\frac{1}{c_{p}} \nabla_{h} J_{0} \cdot \nabla_{h} T-\nabla_{h} T \cdot\left(\nabla_{h} \vec{v}_{g} \cdot \nabla_{h} T\right)\right] \\
& =-\left[\left(T_{x}^{2}+T_{y}^{2}\right)\left(\frac{\partial u_{g}}{\partial x}+\frac{\partial v_{g}}{\partial y}\right)+\left(T_{x}^{2}-T_{y}^{2}\right)\left(\frac{\partial u_{g}}{\partial x}-\frac{\partial v_{g}}{\partial y}\right)\right. \\
& \left.+2 T_{x} T_{y}\left(\frac{\partial v_{g}}{\partial x}+\frac{\partial u_{g}}{\partial y}\right)\right]+2 \nabla_{h}\left(\frac{J_{0}}{c_{p}}\right) \cdot \nabla_{h} T .
\end{aligned}
$$

Thus,

$\frac{D_{g}}{D t}\left|\nabla_{h} T\right|=\frac{1}{\left|\nabla_{h} T\right|}\left[\nabla_{h}\left(\frac{J_{0}}{c_{p}}\right) \cdot \nabla_{h} T-\frac{A}{2}\right]$,

where the term $A$ is given by

$$
\begin{aligned}
A= & \left(T_{x}^{2}+T_{y}^{2}\right)\left(\frac{\partial u_{g}}{\partial x}+\frac{\partial v_{g}}{\partial y}\right) \\
& +\left(T_{x}^{2}-T_{y}^{2}\right)\left(\frac{\partial u_{g}}{\partial x}-\frac{\partial v_{g}}{\partial y}\right)+2 T_{x} T_{y}\left(\frac{\partial v_{g}}{\partial x}+\frac{\partial u_{g}}{\partial y}\right) .
\end{aligned}
$$

By using the stretching deformation and shear deformation defined by

$D_{s t}=\left(\frac{\partial u_{g}}{\partial x}-\frac{\partial v_{g}}{\partial y}\right), \quad D_{s h}=\left(\frac{\partial v_{g}}{\partial x}+\frac{\partial u_{g}}{\partial y}\right)$,

we can rewrite (20) as

$A=\left[\left(T_{x}^{2}-T_{y}^{2}\right) D_{s t}+2 T_{x} T_{y} D_{s h}\right]$,

where divergence of geostrophic velocity is zero. Using matrix operations, (22) can be expressed as

$$
\begin{aligned}
A & =\left[\begin{array}{ll}
T_{x} & T_{y}
\end{array}\right]\left[\begin{array}{cc}
D_{s t} & D_{s h} \\
D_{s h} & -D_{s t}
\end{array}\right]\left[\begin{array}{c}
T_{x} \\
T_{y}
\end{array}\right] \\
& =\left[\begin{array}{ll}
T_{x} & T_{y}
\end{array}\right]\left[\begin{array}{cc}
\cos \delta & \sin \delta \\
-\sin \delta & \cos \delta
\end{array}\right]^{T}\left[\begin{array}{cc}
D & 0 \\
0 & -D
\end{array}\right]\left[\begin{array}{cc}
\cos \delta & \sin \delta \\
-\sin \delta & \cos \delta
\end{array}\right]\left[\begin{array}{c}
T_{x} \\
T_{y}
\end{array}\right],
\end{aligned}
$$


where

$D=\left(D_{s t}^{2}+D_{s h}^{2}\right)^{1 / 2}$,

and the angle of dilation (principal) axis with respect to the horizontal axis $(x)$ is given by

$\delta=\tan ^{-1}\left(D_{s h} /\left(D+D_{s t}\right)\right)$.

It can be shown that

$$
\begin{aligned}
\tan 2 \delta & =\frac{\sin 2 \delta}{\cos 2 \delta}=\frac{2 \sin \delta \cos \delta}{\cos ^{2} \delta-\sin ^{2} \delta}=\frac{2 \tan \delta}{1-\tan ^{2} \delta} \\
& =\frac{2 \frac{D_{s h}}{D+D_{s t}}}{1-\left(\frac{D_{s h}}{D+D_{s t}}\right)^{2}}=\frac{2 D_{s h}\left(D+D_{s t}\right)}{\left(D+D_{s t}\right)^{2}-D_{s h}^{2}}=\frac{2 D_{s h}\left(D+D_{s t}\right)}{2 D_{s t}\left(D+D_{s t}\right)}=\frac{D_{s h}}{D_{s t}} .
\end{aligned}
$$

Thus, $\tan 2 \delta$ is the ratio of the shear deformation to stretching deformation. Note that $\delta \rightarrow 0$ if $D_{s t} \gg D_{s h}$, and $\delta \rightarrow \pi / 4$ if $D_{s h} \gg D_{s t}$.

We can simplify (23) as

$$
\begin{aligned}
A & =D\left[\left(T_{x} \cos \delta+T_{y} \sin \delta\right)^{2}-\left(T_{x} \sin \delta-T_{y} \cos \delta\right)^{2}\right] \\
& =D\left[\left(T_{y}^{2}-T_{x}^{2}\right)\left(\sin ^{2} \delta-\cos ^{2} \delta\right)+4 T_{x} T_{y} \sin \delta \cos \delta\right] \\
& =-D\left|\nabla_{h} T\right|^{2}[\cos 2 \vartheta \cos 2 \delta+\sin 2 \vartheta \sin 2 \delta] \\
& =-D\left|\nabla_{h} T\right|^{2} \cos (2 \vartheta-2 \delta)=-D\left|\nabla_{h} T\right|^{2} \cos (2 \eta),
\end{aligned}
$$

where

$\eta=\vartheta-\delta$, and $\vartheta=\tan ^{-1}\left(-T_{x} / T_{y}\right)$.

Using (27), we finally obtain

$\frac{D_{g}}{D t}\left|\nabla_{h} T\right|=\left[\nabla_{h}\left(\frac{J_{0}}{c_{p}}\right) \cdot \frac{\nabla_{h} T}{\left|\nabla_{h} T\right|}+\frac{1}{2}\left|\nabla_{h} T\right| D \cos (2 \eta)\right]$.

As can be seen in (29), the magnitude of the geostrophic advection of thermal gradient depends on the gradient of $J_{0}\left(=J+S_{p} \omega\right)$ in the direction of $\nabla_{h} T$, and on the deformation term $D$ multiplied by $\cos (2 \eta)$. If we multiply (29) by $R / p$, then we obtain a more familiar form

$\frac{D_{g}}{D t}\left(\frac{R}{p}\left|\nabla_{h} T\right|\right)=\left[\left(\frac{R}{c_{p} p}\right) \nabla_{h} J_{0} \cdot \frac{\nabla_{h} T}{\left|\nabla_{h} T\right|}+\frac{R}{2 p}\left|\nabla_{h} T\right| D \cos (2 \eta)\right]$,

where the second term in the square brackets are identified as the norm of $\mathrm{Q}$ vector projected on $\nabla_{h} T$. The right-hand side of (30), then, represents the source/sink of thermal gradient. (29) indicates that increase in $\left|\nabla_{h} T\right|$ following the geostrophic motion is maximized if $\eta=0$, i.e., when the deformation angle $\delta$ is identical with the angle $\vartheta$. For more information about frontogenesis, see Keyser et al. (1988) and Cohen and Schultz (2005).

\section{References}

Akiyama T (1990) Large, synoptic and meso scale variations of the Baiu front, during July 1982. Part II: frontal structure and disturbances. J Meteorol Soc Jpn Ser II 68:557-574. https://doi. org/10.2151/jmsj1965.68.5_557

Arai M, Kimoto M (2007) Simulated interannual variation in summertime atmospheric circulation associated with the East Asian monsoon. Clim Dyn 31:435-447. https://doi.org/10.1007/s0038 2-007-0317-y

Chen J, Bordoni S (2014) Orographic effects of the Tibetan Plateau on the East Asian summer monsoon: an energetic perspective. J Clim 27:3052-3072. https://doi.org/10.1175/jcli-d-13-00479.1

Chen T-JG, Chang C-P (1980) The structure and vorticity budget of an early summer monsoon trough (Mei-Yu) over southeastern China and Japan. Mon Weather Rev 108:942-953. https://doi. org/10.1175/1520-0493(1980)108\%3c0942:tsavbo\%3e2.0.co;2

Chen H, Sun J (2013) Projected change in East Asian summer monsoon precipitation under RCP scenario. Meteorol Atmos Phys 121:5577. https://doi.org/10.1007/s00703-013-0257-5

Cohen RA, Schultz DM (2005) Contraction rate and its relationship to frontogenesis, the Lyapunov exponent, fluid trapping, and airstream boundaries. Mon Weather Rev 133:1353-1369. https://doi. org/10.1175/mwr2922.1

Dee DP, Uppala SM, Simmons AJ, Berrisford P, Poli P, Kobayashi S, Andrae U, Balmaseda MA, Balsamo G, Bauer P, Bechtold P, Beljaars ACM, van de Berg L, Bidlot J, Bormann N, Delsol C, Dragani R, Fuentes M, Geer AJ, Haimberger L, Healy SB, Hersbach H, Holm EV, Isaksen L, Kallberg P, Köhler M, Matricardi M, McNally AP, Monge-Sanz BM, Morcrette J, Park B, Peubey C, de Rosnay P, Tovolato C, Thepaut J, Vitart F (2011) The ERA-Interim reanalysis: configuration and performance of the data assimilation system. Q J R Meteorol Soc 137:553-597

Holton JR (2004) Introduction to dynamic meteorology, 4th edn. Elsevier, Amsterdam, p 529

Hong J-Y, Ahn J-B (2015) Changes of early summer precipitation in the Korean Peninsula and nearby regions based on RCP simulations. J Clim 28:3557-3578. https://doi.org/10.1175/jcli-d-14-00504.1

Horinouchi T (2014) Influence of upper tropospheric disturbances on the synoptic variability of precipitation and moisture transport over summertime East Asia and the northwestern Pacific. J Meteorol Soc Jpn Ser II 92:519-541. https://doi.org/10.2151/ jmsj.2014-602

Horinouchi T, Hayashi A (2017) Meandering subtropical jet and precipitation over summertime East Asia and the northwestern Pacific. J Atmos Sci 74:1233-1247. https://doi.org/10.1175/ jas-d-16-0252.1

Horinouchi T, Matsumura S, Ose T, Takayabu YN (2019) Jet-precipitation relation and future change of the Mei-Yu-Baiu rainband and subtropical jet in CMIP5 coupled GCM simulations. J Clim 32:2247-2259. https://doi.org/10.1175/jcli-d-18-0426.1

Hoskins BJ (1982) The mathematical theory of frontogenesis. Annu Rev Fluid Mech 14:131-151. https://doi.org/10.1146/annur ev.fl.14.010182.001023

Hoskins BJ, Draghici I, Davies HC (1978) A new look at the $\omega$-equation. Q J R Meteorol Soc 104:31-38. https://doi. org/10.1002/qj.49710443903

Jin Y, Stan C (2019) Changes of East Asian summer monsoon due to tropical air-sea interactions induced by a global warming scenario. Clim Change 153:341-359. https://doi.org/10.1007/ s10584-019-02396-8

Kawase H, Yoshikane T, Hara M et al (2009) Intermodel variability of future changes in the Baiu rainband estimated by the pseudo global warming downscaling method. J Geophys Res. https:// doi.org/10.1029/2009jd011803 
Keyser D, Reeder MJ, Reed RJ (1988) A generalization of Petterssen's frontogenesis function and its relation to the forcing of vertical motion. Mon Weather Rev 116:762-781. https://doi. org/10.1175/1520-0493(1988)116\%3c0762:agopff\%3e2.0.co;2

Kim K-Y (2017) Cyclostationary EOF analysis: theory and applications. SNU press, Texas, p 446

Kim K-Y, North GR (1997) EOFs of harmonizable cyclostationary processes. J Atmos Sci 54:2416-2427. https://doi. org/10.1175/1520-0469(1997)054\%3c2416:eohcp\%3e2.0.co;2

Kim K-Y, North GR, Huang J (1996) EOFs of one-dimensional cyclostationary time series: computations, examples, and stochastic modeling. J Atmos Sci 53:1007-1017. https://doi. org/10.1175/1520-0469(1996)053\%3c1007:eoodct\%3e2.0.co;2

Kim K-Y, Hamlington B, Na H (2015) Theoretical foundation of cyclostationary EOF analysis for geophysical and climatic variables: concepts and examples. Earth Sci Rev 150:201-218. https ://doi.org/10.1016/j.earscirev.2015.06.003

Kimoto M (2005) Simulated change of the east Asian circulation under global warming scenario. Geophys Res Lett. https://doi. org $/ 10.1029 / 2005 \mathrm{gl} 023383$

Kitoh A, Uchiyama T (2006) Changes in onset and withdrawal of the East Asian summer rainy season by multi-model global warming experiments. J Meteorol Soc Jpn 84:247-258. https://doi. org/10.2151/jmsj.84.247

Kodama Y (1992) Large-scale Common features of subtropical precipitation zones (the Baiu frontal zone, the SPCZ, and the SACZ). Part I: characteristics of subtropical frontal zones. J Meteorol Soc Jpn Ser II 70:813-836. https://doi.org/10.2151/ jmsj1965.70.4_813

Lean JL, Rind DH (2008) How natural and anthropogenic influences alter global and regional surface temperatures: 1889 to 2006 . Geophys Res Lett. https://doi.org/10.1029/2008gl034864

Li J, Wu Z, Jiang Z, He J (2010) Can global warming strengthen the East Asian summer monsoon? J Clim 23:6696-6705. https://doi. org/10.1175/2010jcli3434.1

Lim Y-K, Kim K-Y, Lee H-S (2002) Temporal and spatial evolution of the Asian summer monsoon in the seasonal cycle of synoptic fields. J Clim 15:3630-3644. https://doi.org/10.1175/15200442(2002)015\%3c3630:taseot\%3e2.0.co;2

Liu J, Wang B, Cane MA et al (2013) Divergent global precipitation changes induced by natural versus anthropogenic forcing. Nature 493:656-659. https://doi.org/10.1038/nature11784

Liu J, Xu H, Deng J (2018) Projections of East Asian summer monsoon change at global warming of 1.5 and $2{ }^{\circ} \mathrm{C}$. Earth Syst Dyn Discuss 2018:1-25. https://doi.org/10.5194/esd-2018-2

Ninomiya K (1984) Characteristics of Baiu front as a predominant subtropical front in the summer northern hemisphere. J Meteorol Soc Jpn Ser II 62:880-894. https://doi.org/10.2151/jmsj1965.62.6_880

Sampe T, Xie S-P (2010) Large-scale dynamics of the Meiyu-Baiu rainband: environmental forcing by the westerly jet. J Clim 23:113-134. https://doi.org/10.1175/2009jcli3128.1

Seo K-H, Ok J, Son J-H, Cha D-H (2013) Assessing future changes in the East Asian summer monsoon using CMIP5 coupled models. J Clim 26:7662-7675. https://doi.org/10.1175/jcli-d-12-00694.1

Yihui D, Chan JCL (2005) The East Asian summer monsoon: an overview. Meteorol Atmos Phys 89:117-142. https://doi.org/10.1007/ s00703-005-0125-z

Zhang R-H (2015) Natural and human-induced changes in summer climate over the East Asian monsoon region in the last half century: a review. Adv Clim Change Res 6:131-140. https://doi. org/10.1016/j.accre.2015.09.009

Zhou S, Huang G, Huang P (2017) Changes in the East Asian summer monsoon rainfall under global warming: moisture budget decompositions and the sources of uncertainty. Clim Dyn 51:1363-1373. https://doi.org/10.1007/s00382-017-3959-4

Zhu C, Wang B, Qian W, Zhang B (2012) Recent weakening of northern East Asian summer monsoon: a possible response to global warming. Geophys Res Lett. https://doi.org/10.1029/2012g10511 55

Publisher's Note Springer Nature remains neutral with regard to jurisdictional claims in published maps and institutional affiliations. 